Research Article

\title{
Impact of the High-Energy Dynamic Compaction by Multiple Compactors on the Surrounding Environment
}

\author{
Chunlin Jiang $\mathbb{D}^{D}$, Yanhui Ge $\mathbb{D}$, Baoqun Wang $\mathbb{D}^{D}$, Luchen Zhang $\mathbb{D}$, and Youbo Liu \\ School of Civil Engineering, Shandong Jiaotong University, Jinan 250357, China \\ Correspondence should be addressed to Yanhui Ge; nepenthes@163.com
}

Received 17 December 2020; Revised 3 September 2021; Accepted 1 November 2021; Published 29 November 2021

Academic Editor: Walid Oueslati

Copyright (c) 2021 Chunlin Jiang et al. This is an open access article distributed under the Creative Commons Attribution License, which permits unrestricted use, distribution, and reproduction in any medium, provided the original work is properly cited.

\begin{abstract}
Dynamic compaction machine (DCM) is a widely adopted ground reinforcement technology. However, dynamic compaction energy has a very significant impact on the surrounding environment. At present, the research on the impact of dynamic compaction mainly focuses on the effect of the tamping behavior of a single compactor in the working state, whereas the research on the impact of multiple compactors working jointly is rare. To study the impact of the dynamic compaction energy of multiple compactors working jointly on the surrounding environment, the dynamic response model for multiple compactors working in the same field was established based on the explicit dynamic analysis module in ABAQUS. The validity of the model was verified by comparison with the measured data. Based on this, the impact of the dynamic compaction energy of multiple compactors with different working conditions in terms of the arrangement, spacing, and working time interval was analyzed. The results showed that the arrangement and spacing of the compactors had a remarkable influence on the distribution of the dynamic compaction energy in the surrounding environment. Under the condition of multiple compactors working with a time interval of less than $10 \mathrm{~s}$, the impact of the superimposed dynamic compaction energy due to the interaction of multiple compactors had to be considered.
\end{abstract}

\section{Introduction}

The dynamic compaction method is a foundation reinforcement method that was first presented in 1969 by Menard Technology Company of France. Reinforcement by dynamic compaction machine (DCM) is a widely applicable, economical, and effective ground treatment method that can significantly shorten a construction period and save project investment. It has produced good economic and social benefits in the field of Chinese engineering construction. However, its shortcomings should also not be ignored. In recent years, with the quickening pace of urban construction, more and more buildings have been built on soft foundations. The adverse effects from the dynamic vibration and construction noise on the surroundings and buildings have also become increasingly serious [1-5].

Thus far, experts around the world have studied the impact of DCM on the surrounding environment based mainly on experiments and numerical simulations. For most of the numerical simulations, the finite element method was used, along with a few other methods [6-11]. During dynamic compaction construction, tamping energy is converted into dynamic stress propagation in soil. In addition to compacting the soil and reinforcing the ground, part of the energy propagates in the form of transverse waves and Rayleigh waves, causing the vibration of the ground and the surrounding environment. Fang et al. [12] noted that the maximum amplitude of DCM gradually decreases with the increase in the number of tamps. Li et al. [13] found that the maximum peak acceleration and the velocity of DCM vibration decreased rapidly with the increase in the distance from the vibration source while continuously increasing with the increase in the number of tamps [14]. Peng derived the theoretical formula for calculating the velocity of stratum vibration by measuring the vertical vibration velocity of particles and using the simplified model of DCM vibration. Son et al. [15] analyzed the acceleration and spectral characteristics of a gravel wall, and the acceleration change 
equation based on the distance from the gravel wall was proposed. Mostafa [16] studied the finite element simulation method of a falling hammer impact; a constitutive model of cohesive soil was proposed in order to express the dynamic compaction. Moon et al. [17] studied the characteristics of a foundation during dynamic compaction. These characteristics were evaluated under different compaction energy conditions. Zhang et al. [18] studied the factors affecting DCM and geogrid reinforcement. In addition, relevant research found that the DCM energy decayed quickly with the increasing distance. Zhang et al. [19] analyzed the variation law of the displacement field, stress field, and plastic zone of the embankment body reinforced by dynamic compaction with different energy levels and the optimal compaction energy by means of numerical simulations and field tests. At present, it is considered that the amplitude of a ground vibration generally decays in the form of a negative power function [20-22].

The above studies of DCM energy were mainly targeted at single compactors. Some researchers who studied compactor groups largely focused on the influence of various dynamic compaction parameters on the soil reinforcement performance [23-26]. However, relevant research on the impact of multiple compactors working jointly on the surrounding environment is lacking. Currently, the most widely adopted engineering practice involves the use of multiple compactors with the joint consideration of factors such as construction time and cost.

For multiple DCM (Figure 1), considering their impact as a weak explosion, according to Anderson's linear superposition formula [27], the vibration at the measuring point $x$ caused by multiple impact sources (multiple DCM) can be obtained:

$$
u(x, t)=m(\xi, \tau) \cdot G(x, t, \xi, \tau),
$$

where $m(\xi, \tau)$ stands for the time function of multiple impact sources, $G(x, t, \xi, \tau)$ is the elastic dynamic Green function, $\xi$ is the position of shock source, $t$ is the time, and $\tau$ is the Green function variable.

Based on formula (1), vibration $u_{s}$ and source function $m_{s}$ caused by a single DCM hammer can be expressed as follows:

$$
u_{s}=m_{s} \cdot G
$$

Rewritten the multiple impact sources time function $\mathrm{m}$ as a pulse sequence related to single hammer vibration:

$$
\begin{aligned}
m & =m_{s} \cdot m_{R}, \\
m_{R} & =\sum_{i=1}^{n} a_{i} \delta\left(t-t_{i}\right), i=1,2, \ldots, n,
\end{aligned}
$$

where $m_{R}$ is the pulse sequence function, $a_{i}$ stands for the vibration ratio coefficient of the pulse $i, \delta$ is the Dirac pulse function, $t$ is the impact time interval, and $n$ is the number of pulses (DCM hammer).

Due to the nonlinearity of soil, the propagation of shockinduced vibration waves in a stratum is a complicated process. Its attenuation law is affected by the site conditions

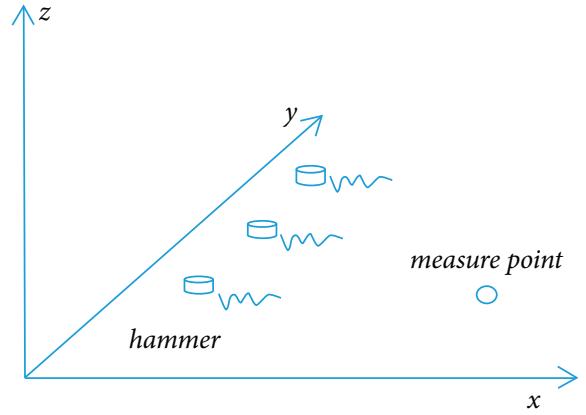

Figure 1: Multiple DCM impact energy superposition diagram.

and the properties of rock and soil. The empirical formulas of ground vibration intensity and site nonlinearity summarized by scholars from various countries based on experimental data (such as the Sadovsky formula) are mostly generalized expressions similar to the following expression:

$$
A=K \cdot Q^{\alpha} \cdot R^{\beta},
$$

where $A$ is the vibration intensity, $Q$ is the impact energy, $R$ is the distance between the measuring point and the impact point, $K$ is the empirical coefficient related to the design parameters of the impact source, $\alpha$ and $\beta$ are the attenuation coefficients determined by the site conditions and the properties of rock and soil, which are generally obtained through field test data analysis.

Finally, based on the above analysis, the ground vibration caused by the superposition of multiple DCM impacts can be expressed as follows:

$$
u=u_{s} \cdot \sum_{i=1}^{n} K\left(\frac{Q_{i}}{Q_{0}}\right)^{\alpha} \delta\left(t-t_{i}\right)
$$

where $Q_{i}$ is the tamping energy, $K$ is the empirical coefficient related to the parameters of DCM, and $\alpha$ is the attenuation coefficient determined by the site conditions and the properties of rock and soil.

Formula (5) is a description of the ground vibration intensity caused by the superposition of multiple DCM vibration energy, but DCM impact, in reality, is not ideal pulses in formulas; the complexity of DCM impact and site condition restricts its application. To solve this problem, the numerical model of multiple DCM is established based on ABAQUS/explicit dynamic finite element module, and the superposition of dynamic compaction vibration is studied.

The damping of soil vibration in numerical simulation can be achieved by energy conservation. By the first law of thermodynamics states, the time rate of change of kinetic energy and internal energy for a fixed body of material is equal to the sum of the rate of work done by the surface and body forces. This can be expressed as follows:

$$
\frac{\mathrm{d}}{\mathrm{d} t} \int_{V}\left(\frac{1}{2} \rho v \cdot v+\rho U\right) d V=\int_{S} v \cdot t \mathrm{~d} S+\int_{V} f \cdot v \mathrm{~d} V,
$$

where $\rho$ is the current mass density, $v$ is the velocity field vector, $U$ is the internal energy per unit mass, $t$ is the surface 
traction vector, $f$ is the body force vector, and $n$ is the normal direction vector on boundary $S$.

With $t=\sigma \cdot n$ on the boundary $S$, we get:

$$
\int_{S} v \cdot t \mathrm{~d} S=\int_{V}\left(\frac{\partial}{\partial x}\right) \cdot(v \cdot \sigma) \mathrm{d} V=\int_{V}\left[\left(\frac{\partial}{\partial x} \cdot \sigma\right) \cdot v+\dot{\varepsilon}: \sigma\right] \mathrm{d} V .
$$

Then the formula (6) can be rewritten as follows:

$$
\frac{\mathrm{d}}{\mathrm{d} t} \int_{V}\left(\frac{1}{2} \rho v \cdot v+\rho U\right) \mathrm{d} V=\int_{V}\left[\left(\frac{\partial}{\partial x} \cdot \sigma+f\right) \cdot v+\sigma: \dot{\varepsilon}\right] \mathrm{d} V,
$$

$$
\int_{V} \frac{1}{2} \rho v \cdot v d V+\int_{V} \rho U d V=\int_{0}^{t} \dot{E}_{W F} d \tau+\text { constant }
$$

or,

$$
E_{K}+E_{U}=\int_{0}^{t} \dot{E}_{W F} d \tau+\text { constant }
$$

where $E_{K}=\int_{V} 1 / 2 \rho v \cdot v \mathrm{~d} V$ is the kinetic energy, $E_{U}=\int_{V} \rho U \mathrm{~d} V=\int_{0}^{t}\left(\int_{V} \sigma: \dot{\varepsilon} \mathrm{d} V\right) \mathrm{d} \tau-U_{0}\left(U_{0}\right.$ is the energy at time 0 ) is the internal energy, and the rate of work done to the body by external forces and contact friction forces between the contact surfaces $\dot{E}_{W F}$ is defined as follows:

where $\dot{\varepsilon}$ is the strain rate tensor. Using Cauchy's equation of motion and integrating this equation, we get

$$
\dot{E}_{W F}=\left(\int_{S} v \cdot t^{l} \mathrm{~d} S+\int_{V} f \cdot v \mathrm{~d} V\right)-\left(-\int_{S} v \cdot t^{f} \mathrm{~d} S\right)-\left(-\int_{S} v \cdot t^{q b} \mathrm{~d} S\right) \equiv \dot{E}_{W}-\dot{E}_{F}-\dot{E}_{\mathrm{QB}},
$$

where $\dot{E}_{W}$ is the rate of work done to the body by external forces, $\dot{E}_{Q B}$ is the rate of energy dissipated by the damping effect of solid medium infinite elements, and $\dot{E}_{F}$ is the rate of energy dissipated by contact friction forces between the contact surfaces. An energy balance for the entire model can then be written as follows:

$$
E_{U}+E_{K}+E_{F}-E_{W}-E_{Q B}=\text { constant, }
$$

where the dissipated portions of the internal energy $E_{U}$ can be split off as follows:

$$
E_{U}=\int_{0}^{t}\left(\int_{V} \sigma^{c}: \dot{\varepsilon} \mathrm{d} V\right) d \tau+\int_{0}^{t}\left(\int_{V} \sigma^{v}: \dot{\varepsilon} \mathrm{d} V\right) \mathrm{d} \tau \equiv E_{I}+E_{V},
$$

where $\sigma^{c}$ is the stress derived from the user-specified constitutive equation, $\sigma^{v}$ is the viscous stress, $E_{V}$ is the energy dissipated by viscous effects (determined by setting bulk viscosity, material damping, and dashpots in the model), and $E_{I}$ is the remaining energy can be expressed as follows:

$$
\begin{array}{r}
E_{I}=\int_{0}^{t}\left(\int_{V} \sigma^{c}: \dot{\varepsilon}^{e l} \mathrm{~d} V\right) \mathrm{d} \tau+\int_{0}^{t}\left(\int_{V} \sigma^{c}: \dot{\varepsilon}^{p l} \mathrm{~d} V\right) \mathrm{d} \tau+\int_{0}^{t}\left(\int_{V} \sigma^{c}: \dot{\varepsilon}^{c r} \mathrm{~d} V\right) \mathrm{d} \tau \\
=E_{S}+E_{P}+E_{C}
\end{array}
$$

where $\dot{\varepsilon}^{e l}, \dot{\varepsilon}^{p l}, \dot{\varepsilon}^{c r}$ are elastic, plastic, and creep strain rates, respectively; $E_{S}$ is the applied elastic strain energy; $E_{P}$ is the energy dissipated by plasticity; and $E_{C}$ is the energy dissipated by time-dependent deformation (creep, swelling, and viscoelasticity).

Through the above formulas, according to the energy conservation theory, the dissipation and attenuation of soil vibration energy can be realized in the model, and the stress and strain of soil elements can be obtained by dynamic balance.
Considering soil as a homogeneous continuous medium with an elastic-plastic constitutive relationship, the node equilibrium equation can be obtained according to the principle of virtual work as follows:

$$
[M]^{e}\{\ddot{\delta}\}+[C]^{e}\{\dot{\delta}\}^{e}+[K]_{e p}^{e}\{\delta\}^{e}=\left\{F_{(t)}\right\}^{e},
$$

where $[M]^{e}$ is the mass matrix; $[C]^{e}$ is the damping matrix; $[K]_{e p}^{e}$ is the stiffness matrix of the element; $\ddot{\delta}, \tilde{\delta}, \delta$ are node velocity vector, acceleration vector, and displacement vector, respectively; $F_{(t)}{ }^{e}$ is equivalent node load vector; and

$$
[M]^{e}=\iiint_{v}[N]^{T} \rho[N] \mathrm{d} v,[K]_{e p}^{e}=\iint_{v}[B]^{T}[\bar{D}]_{e p}[B] \mathrm{d} v,[\bar{D}]_{e p}=m[D]_{e}+(1-m)[D]_{e p},[D]_{e p}=[D]_{e}-\frac{[D]_{e}\{\partial Q / \partial \sigma\}\{\partial F / \partial \sigma\}^{T}[D]_{e}}{H \prime+\{\partial Q / \partial \sigma\}^{T}\{\partial F / \partial \sigma\}[D]_{e}}
$$


where $[D]_{e p}$ is the elasto-plastic matrix, $[D]_{e}$ is the elastic matrix, $[N]$ is the interpolation function that depends on node coordinate, $Q$ is the plastic potential function, $H^{\prime}$ is the hardening modulus, and $F$ is the yield function; in this paper, the yield function of ABAQUS built-in Mohr-Coulomb model is used as follows:

$$
\begin{aligned}
F & =R_{m c} q-p \tan \varphi-c=0 \\
R_{m c}(\Theta, \varphi) & =\frac{1}{\sqrt{3} \cos \varphi} \sin \left(\Theta+\frac{\pi}{3}\right)+\frac{1}{3} \cos \left(\Theta+\frac{\pi}{3}\right) \tan \phi
\end{aligned}
$$

where $c$ is cohesion, $\varphi$ is the friction angle, $q$ is the generalized shear stress, $R_{m c}$ is the Mohr-Coulomb deviatoric stress measure, and $\Theta$ is the deviatoric polar angle.

The essence of the ABAQUS/Explicit explicit algorithm is to replace differential by difference, calculate displacement and acceleration by linear interpolation, and conduct explicit time integration by central difference method, then formula (14) can be expressed as follows:

$$
M_{i j} \ddot{u}_{j}(t+\Delta t)+C_{i j} \dot{u}_{j}(t+\Delta t)+K_{i j} u_{j}(t+\Delta t)=P_{i}(t+\Delta t),
$$

where $M$ is mass, $C$ is damping, $K$ is stiffness, $P$ is external force, and $\ddot{u}, \dot{u}, u$ are acceleration, velocity, and displacement of nodes, respectively.

The propagation of dynamic compaction vibration and the process of its energy attenuation are the focus of simulation analysis. Through the analysis of the action mechanism of longdistance soil affected by dynamic compaction vibration, the Rayleigh damping of soil material is set in ABAQUS.

Rayleigh damping in ABAQUS is a linear combination of mass matrix $M$ and stiffness matrix $K$, as follows:

$$
C=\alpha M+\beta K,
$$

where $\alpha$ and $\beta$ are damping coefficients, which can be solved by the damping ratio and natural frequency of soil structure.

For damped systems, the stability limit in the simulation is defined as follows:

$$
\Delta t_{\text {stable }}=\frac{2}{\omega_{\max }}\left(\sqrt{1+\xi^{2}}-\xi\right),
$$

where $\xi$ is the critical damping ratio of the model under the highest vibration circular frequency. Since the maximum vibration frequency of the model is determined by a series of complex interaction factors, it is difficult to obtain its accurate value; the stability limit in ABAQUS is defined by element length and material wave velocity as follows:

$$
\begin{aligned}
\Delta t_{\text {stable }} & =\frac{L_{e}}{C_{d},} \\
C_{d} & =\sqrt{\frac{E}{\rho}},
\end{aligned}
$$

where $E$ is the elastic modulus of the material and $\rho$ is the density of the material.
Based on the above analysis and using the ground treatment project of the line R1 vehicle base of Jinan Rail Transit as a case example (Rayleigh damping coefficients $\alpha=0.11$ and $\beta=0.0155$ ), the working state of multiple compactors for high-energy dynamic compaction reinforcement was simulated. Additionally, the impact of common multiple compactor arrangements on the surrounding environment was analyzed in order to provide a reference for the design and construction of the relevant dynamic compaction projects.

\section{Model Parameters}

2.1. Soil Constitutive Model. In the analysis of dynamic compaction, factors such as the dynamic impact of DCM and the hammer-soil interaction must be comprehensively considered in the soil constitutive model. Considering the aim of this study and the nature of the project example, the Mohr-Coulomb model was selected as the constitutive model of the model soil from a variety of built-in soil constitutive models in ABAQUS.

The Mohr-Coulomb model in ABAQUS is an extension of classic models, and it has been widely used in many geotechnical analyses with sufficient accuracy. The main mechanical parameters of the model include the elastic modulus $E$, Poisson's ratio $\mu$, cohesion, and internal friction angle of soil. Based on the trial calculation of the relevant laboratory geotechnical test data and the actual measurement data in the early stage of the project, the relevant parameters used in the analysis were determined, as shown in Table 1.

2.2. Hammer Impact. The focus of this study was to examine the impact of the DCM energy of multiple compactors on the surrounding environment. Therefore, the hammer falling process in dynamic compaction was omitted, and a vertical initial velocity consistent with the free-fall formula was used for the hammer model rather than in combination with the volume and mass of the hammer in order to assign high tamping energy of $4,000 \mathrm{kN} \cdot \mathrm{m}$ to the hammer. The contact between the hammer and the soil was achieved by a penalty function algorithm.

2.3. Site Boundary Conditions. The artificial boundary of the dynamic analysis model had to not only reflect the radiation of the waves in the soil layer but also ensure that the vibration wave did not produce a notable reflection effect when it crossed the boundary from inside the analysis area. The coupling boundary between the finite element and the infinite element had good attenuation characteristics, which could effectively eliminate the reflection of the vibration wave on the artificial boundary. The energy and the deformation in the area near the vibration source were large, while the deformation in the area far from the vibration source was small. Therefore, the center area of the site calculation model could be simulated by the finite element method, considering the soil heterogeneity, nonlinearity, and stratigraphic interface. In comparison, the soil in the edge area of the model had relatively small deformation, and it could be approximated as an elastic medium, 
TABLE 1: Soil parameters.

\begin{tabular}{lccccc}
\hline Position & Modulus of elasticity, $E(\mathrm{MPa})$ & Poisson's ratio, $\mu$ & Cohesion, $c(\mathrm{kPa})$ & Internal friction angle, $\varphi\left(^{\circ}\right)$ & Density $\left(\mathrm{kg} / \mathrm{m}^{3}\right)$ \\
\hline Topsoil & 6.7 & 0.38 & 21 & 28.7 & 1,830 \\
Deep soil & 210 & 0.3 & 6 & 29.5 & 1,900 \\
Hammer & $2.11 \times 104$ & 0.22 & - & - & 7,800 \\
\hline
\end{tabular}

which could be suitably discretized by infinite elements to establish the radiation boundary conditions for the vibration wave to propagate to infinity. This type of boundary was selected as the site boundary condition of the model in this study to simulate the characteristics of infinite half-space soil, as shown in Figure 2.

2.4. Model Setup and Verification. In reference to the data from relevant literature sources [5-7], the frequency of the ground vibration caused by DCM was lower than $10 \mathrm{~Hz}$, and the wavelength of the Rayleigh wave, which was the main factor affecting the surrounding environment, was usually between $8 \mathrm{~m}$ and $12 \mathrm{~m}$. Therefore, in the model, the size of the element in the tamping loading area in contact with the hammer and the ground soil was set to $0.5 \mathrm{~m}$, and the size of the impacted area was set to $0.8 \mathrm{~m}$. The element size could be appropriately increased in nonloading areas and edge areas to meet the accuracy requirement and reduce the computing cost.

The model was $560 \mathrm{~m}$ long and $400 \mathrm{~m}$ wide with a $30 \mathrm{~m}$ thick soil layer, and it was established using a total of 1.52 million three-dimensional solid elements. In line with the engineering practice, a trapezoidal vibration isolation ditch with both a width and a depth of $3 \mathrm{~m}$ was arranged at the edge of the working area of the compactors. To prevent the vibration wave from reflecting from the model boundary to the inside and to avoid additional, nonconforming vibration, a buffer area was reserved outside the main observation and analysis area. The specific mesh is shown in Figure 3.

To verify the reliability of the results of the numerical calculation, a trial analysis was first carried out, and a numerical model was established under typical tamping conditions for simulation analysis and calculation. The numerical results were compared with the measured results to verify the reliability of the calculation results. The results proved that the model could accurately reflect the impact of the DCM energy on the nearby buildings. The detailed comparison is shown in Figure 4.

2.5. Influence of DCM Vibration. Based on the vibration theory, it is obvious that the impact range and vibration peak velocity of dynamic compaction projects with multiple rammers are higher than those of a single rammer, and the dynamic compaction vibration will have a significant impact on the surrounding buildings (structures) and precision instruments.

Table 2 lists the allowable vibration of buildings in China Standard for Allowable Vibration of Building Engineering (GB 50868-2013; DCM Vibration Frequency 1-10 Hz).

Vibration beyond this standard will cause a series of adverse consequences, such as building cracking, data error

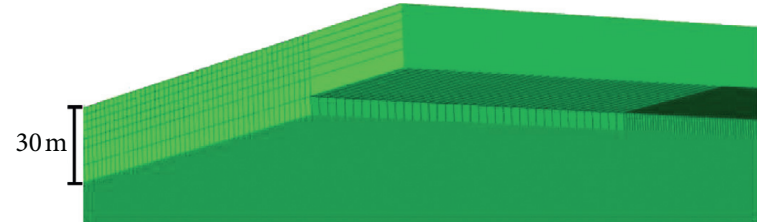

Figure 2: The coupled finite infinite element boundary.

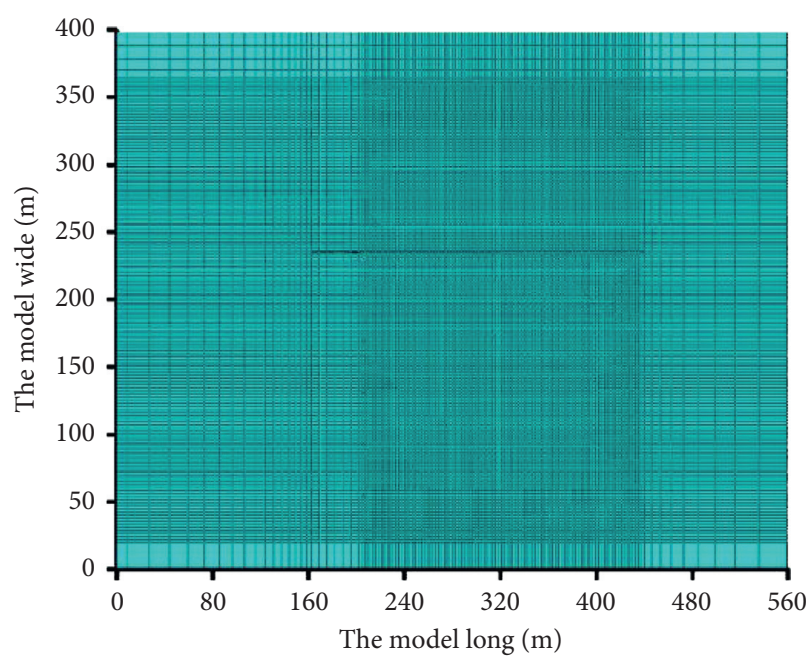

FIgUre 3: Schematic diagram of the model mesh.

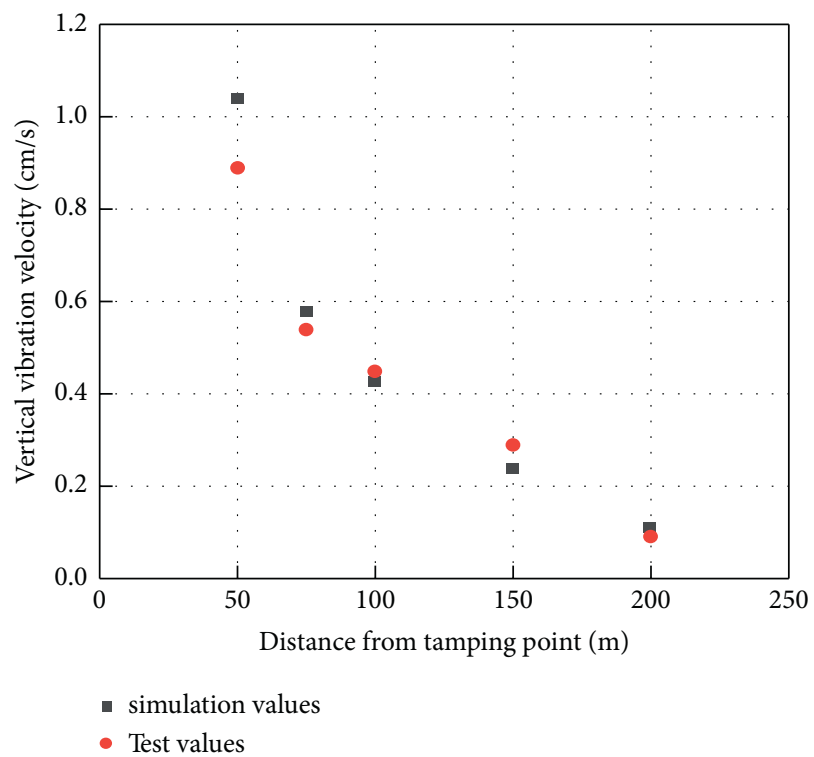

FIgURE 4: Comparison of the trial compaction test values and the numerical simulation values. 
TABLE 2: Allowable vibration of the architectural structures.

\begin{tabular}{|c|c|c|c|}
\hline \multirow[t]{2}{*}{ Building type } & \multirow{2}{*}{$\begin{array}{l}\text { Allowable peak vibration velocity of the } \\
\text { top floor }(\mathrm{mm} / \mathrm{s}) \\
\qquad 1-50 \mathrm{~Hz}\end{array}$} & \multicolumn{2}{|c|}{$\begin{array}{l}\text { Basic allowable } \\
\text { peak vibration } \\
\text { velocity }(\mathrm{mm} / \\
\text { s) }\end{array}$} \\
\hline & & $1-10 \mathrm{~Hz}$ & $50 \mathrm{~Hz}$ \\
\hline Industrial and public buildings & 24.0 & 12.0 & 24.0 \\
\hline Residential buildings & 12.0 & 5.0 & 12.0 \\
\hline $\begin{array}{l}\text { Buildings sensitive to vibration that also have a protective value that cannot be } \\
\text { classified into the above two categories }\end{array}$ & 6.0 & 3.0 & 6.0 \\
\hline
\end{tabular}

The allowable vibration was determined by the frequency linear interpolation.

or even damage to precision instruments, and physical discomfort of staff members. Therefore, it is necessary to study the superposition of vibration energy of multiple DCM.

\section{Analysis of the Impact of the Arrangement of Multiple Compactors}

3.1. Compactor Arrangement. After comprehensive consideration of the actual construction situation and safety, the minimum distance between two compactors was set to $15 \mathrm{~m}$, with the arrangements in the east-west direction $(\mathrm{H})$ and the north-south direction (V). As shown in Figure 5, the cloud plot of the peak vertical vibration velocity of the ground shows that when the ground was tamped by two hammers simultaneously, ground vibrations were clearly superposed at the site. Figure 5 .

Figure 6 shows the trend in the variation curve of the peak vertical vibration velocity with time at each measuring point for the two-hammer condition with different arrangements. As can be seen from the figure, for the east-west "horizontal arrangement," the ground vibration amplitude in the area close to the tamping points increased significantly, and the vertical peak vibration velocity showed an attenuation trend similar to that of a single hammer. That is, it also decreased rapidly with time. For the north-south "vertical arrangement," the ground vibration amplitude in the area close to the tamping points did not vary significantly. However, as the vibration of the second hammer propagated, multiple peaks clearly appeared in the vertical vibration velocity of the ground, and the extent of attenuation over time was less than that for the east-west horizontal arrangement condition. The specific data at measuring points with different distances are compared in Figure 6.

It can be seen from Figure 7 that the peak vertical vibration velocity of the ground near the tamping point was remarkably higher in the east-west direction than in the north-south direction. The difference between the two gradually decreased in the ground that was slightly distant from the tamping point. In the distant ground, the distance factor caused the peak vertical vibration velocity to start to be lower in the north-south direction than in the east-west direction. At a distance of $200 \mathrm{~m}$, the difference between the two became insignificant, and their impacts on the ground were essentially the same.
Therefore, for the condition of two compactors working simultaneously, if a key built structure is located in the nearfield range $(<50 \mathrm{~m})$ that is close to a tamping point, a vertical arrangement would be best selected in the north-south direction parallel to the line connecting the structure and the tamping point. If a key structure is located in the mid-field range $(<100 \mathrm{~m})$ that is far from a tamping point, a horizontal arrangement should be chosen in the east-west direction perpendicular to the line connecting the structure and the tamping point. If the key structure is located in a far-field range $(>200 \mathrm{~m})$ that is very far from a tamping point, the arrangement of compactors has no significant impact.

3.2. Distance between Compactors. The distance between compactors is an important factor that influences the superposition of tamping energy and the vibration of two hammers. The numerical models of tamping by two hammers with different distances were established according to different arrangements. The results are shown in Figures 7 and 8 .

It can be seen from Figures 8 and 9 that when the two hammers were too close to each other, there was significant interference and relatively pronounced energy superposition in the direction perpendicular to the line connecting the two hammers. The ground vibration near the line perpendicular to the line connecting the two hammers was very complicated, and the surrounding area was severely impacted.

It can be seen from Figure 10 that as the distance between the two compactors increased the peak vertical vibration velocity of the soil in the near-field range gradually decreased, but it still had a large value, proving that the nearfield range was still affected even if the distance increased. In the mid-field range, as the distance increased, the amplitude of the peak vertical vibration velocity varied only slightly; the peak appeared with a delay; and the rate of energy attenuation gradually decreased. For the soil in the far-field range, the amplitude of the peak vertical vibration velocity was always small, and it did not vary significantly, being essentially similar to that of the single compactor case.

It can be seen from Figure 11 that when the two compactors were arranged vertically, as the distance increased, the soil in the near-field range was affected the most. There were multiple peaks, and the energy attenuated at a significantly slower rate. In the mid-field range, as the distance between compactors increased, the amplitude of the peak vertical vibration velocity decreased, 


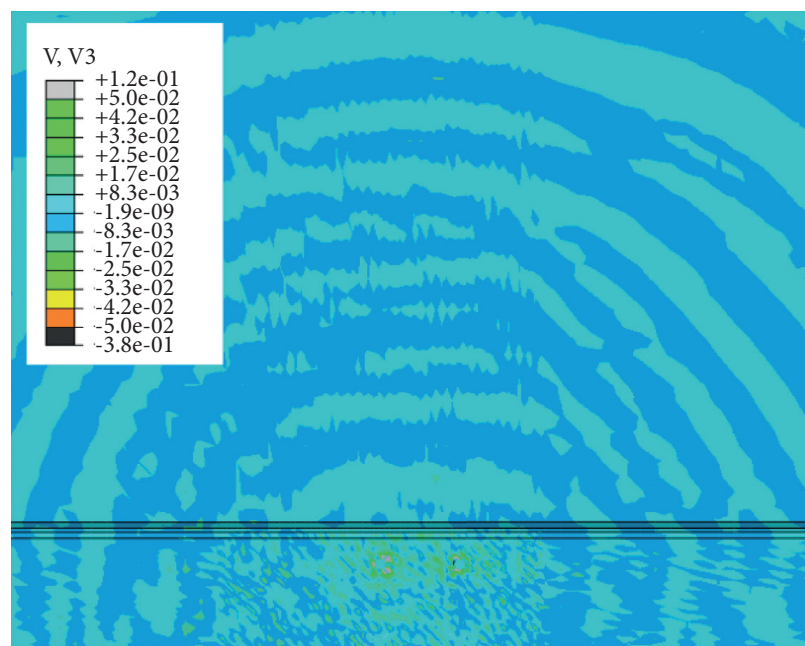

(a)

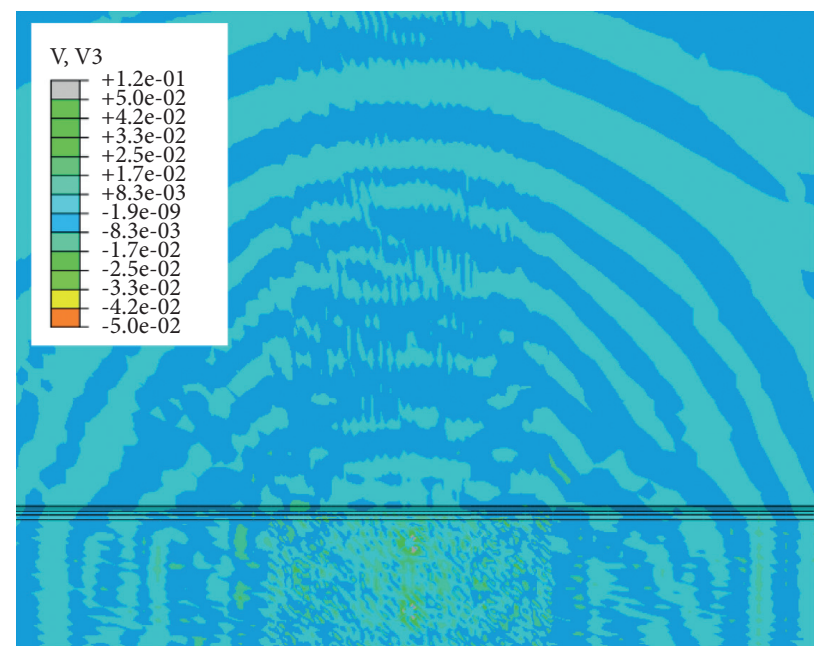

(b)

Figure 5: Nephogram of the peak vertical vibration velocity of the ground during two-hammer compaction for different compactor arrangements (m/s): (a) east-west direction and (b) north-south direction.

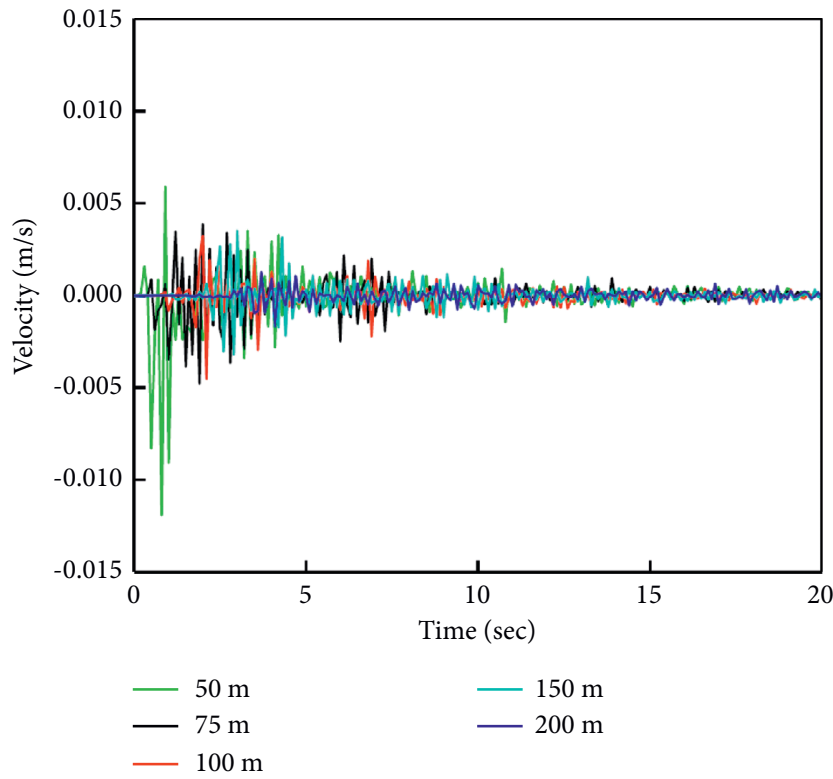

(a)

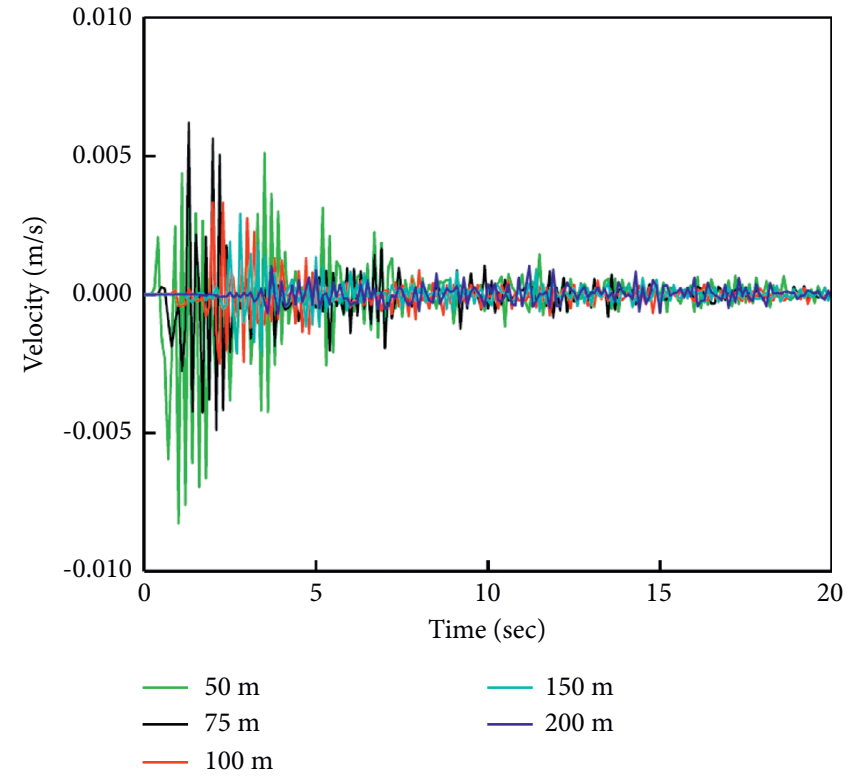

(b)

FIGURE 6: Time-history curves of the peak vertical vibration velocities at different measuring points during double-hammer compaction for different compactor arrangements: (a) east-west $(\mathrm{H})$ arrangement and (b) north-south (V) arrangement.

but the peak vertical vibration velocity appeared with a significant delay. For the soil in the far-field range, the peak vertical vibration velocity maintained a relatively small amplitude, while the peak appeared with a remarkable delay. The energy attenuation trend was essentially similar to that of the single hammer case. Compared with that for the horizontal arrangement, as the distance increased, the impact of the energy superposition decreased remarkably, but the peak appeared much later for the vertical arrangement.
3.3. Time Interval between Compactors. To study the energy superposition of two compactors working at different times, a model of two compactors landing at different time intervals was established for analysis. The results are shown in Figure 11.

Figure 12 is the cloud plot showing the distribution of the peak vertical vibration velocity of the ground $2 \mathrm{~s}$ after the hammer of the second compactor in a horizontal arrangement landed on the ground. It can be seen from the figure that when the time interval between the two hammers was less than $5 \mathrm{~s}$, the tamping energy of the second hammer had a 


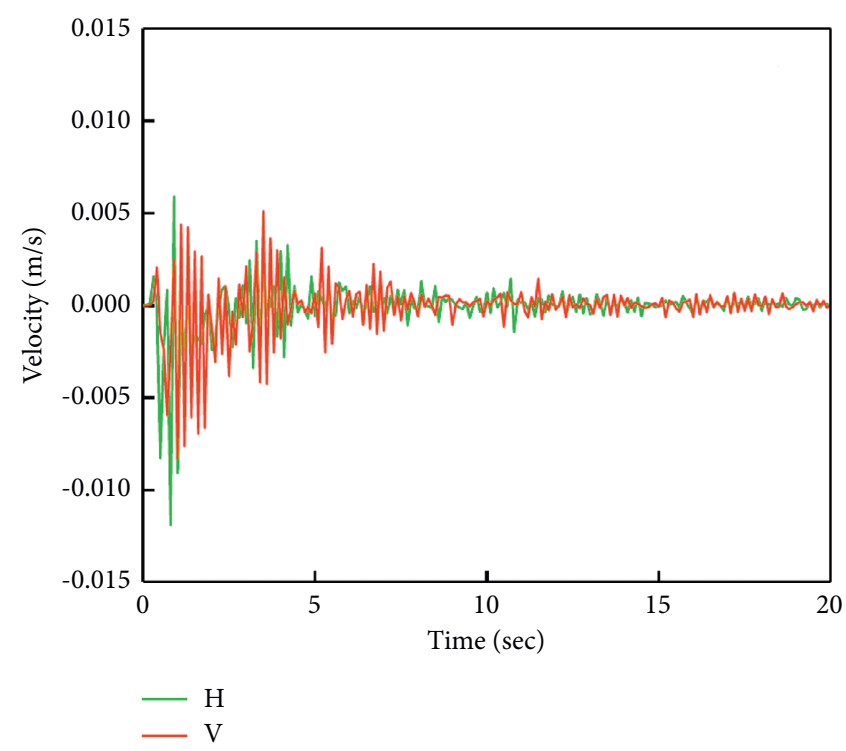

(a)

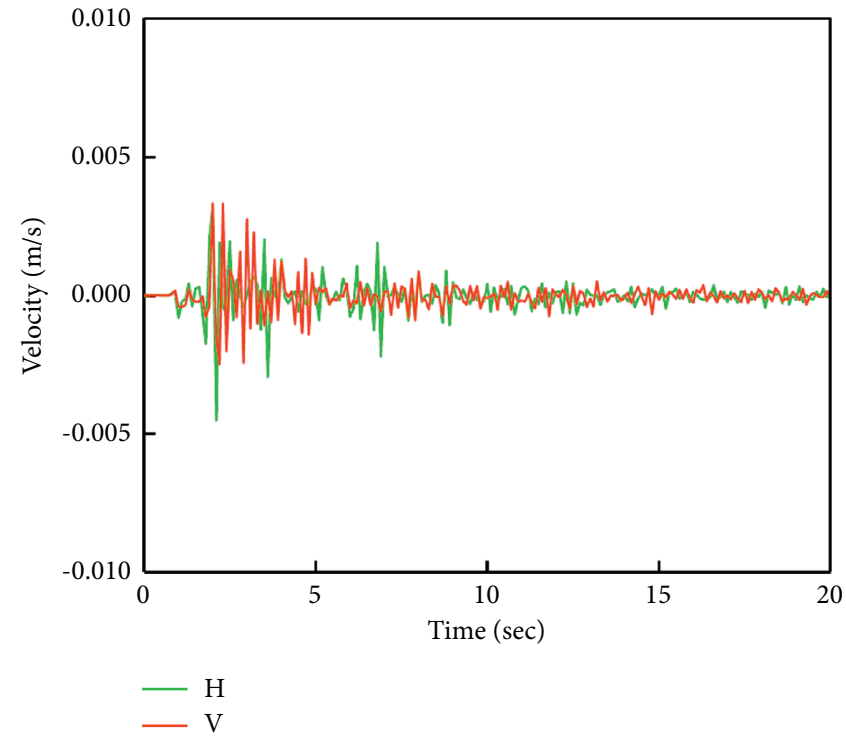

(c)

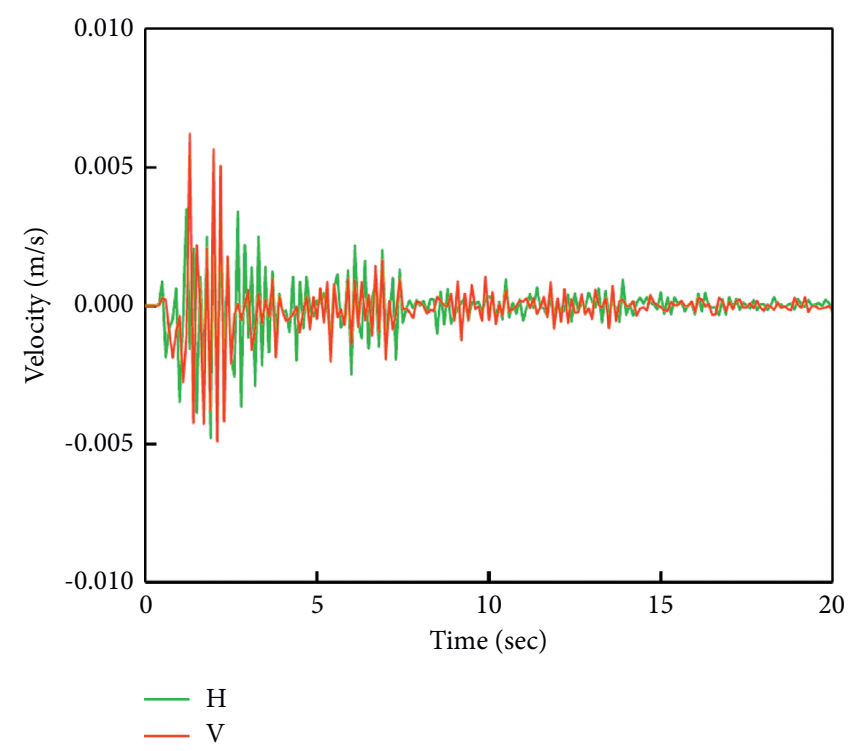

(b)

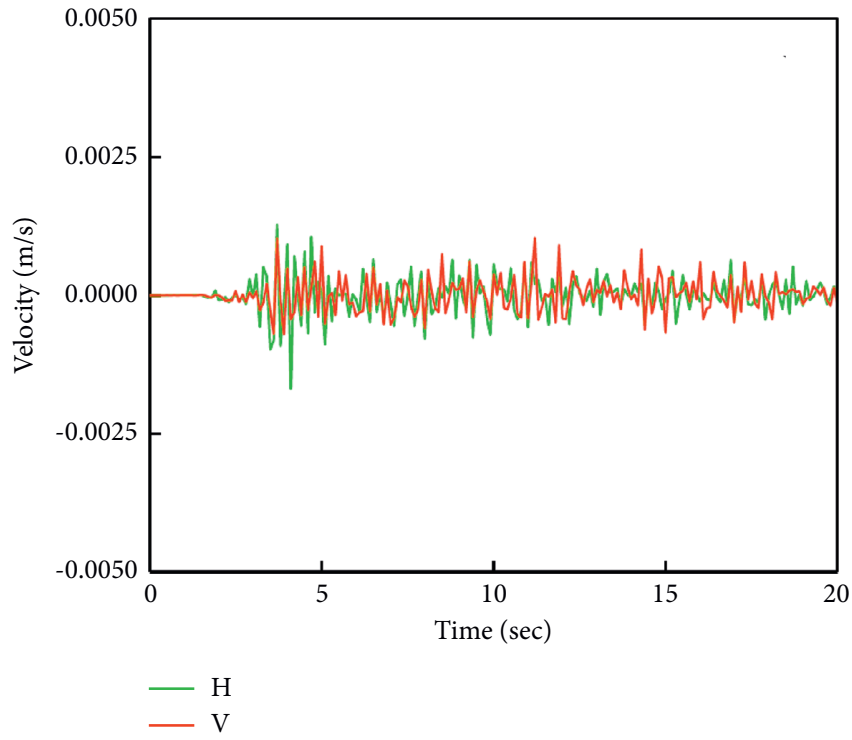

(d)

Figure 7: Time-history curves of the peak vertical vibration velocities at different measuring points with different distances: (a).50 $\mathrm{m}$ measuring point, (b) $75 \mathrm{~m}$ measuring point, (c) $100 \mathrm{~m}$ measuring point, and (d) $200 \mathrm{~m}$ measuring point.

significant influence on the peak vertical vibration velocity of the ground. When the time interval between the two hammers was longer than $5 \mathrm{~s}$, the trend of ground vibration caused by the tamping energy of the second hammer was essentially similar to that of the single hammer compaction case. The vibration velocity analysis is detailed in Figure 12.

It can be seen from Figure 13 that for the working condition of two hammers with a time interval of less than $5 \mathrm{~s}$, the energy was significantly superimposed; the peak vertical vibration velocity increased; multiple peaks appeared; and the trend of attenuation with time became remarkably slow. As the time interval increased, the energy began to be less superimposed, and when the time interval was longer than $8 \mathrm{~s}$, the energy superposition was essentially the same as that of the single hammer compaction case.

For soil in the near-field range, hammering with a time interval of less than $10 \mathrm{~s}$ resulted in significant energy superposition, the occurrence of multiple peaks, and a slower trend of the energy attenuation. For the mid-field range, the energy superposition caused by hammering with a time interval greater than $5 \mathrm{~s}$ became insignificant, and the energy attenuation trend was close to the single hammer state. For the far-field range, the superposition of tamping energies with a time interval longer than $5 \mathrm{~s}$ could be generally ignored, and compactions with a time interval of $10 \mathrm{~s}$ could be regarded as two different single-hammer compactions. 


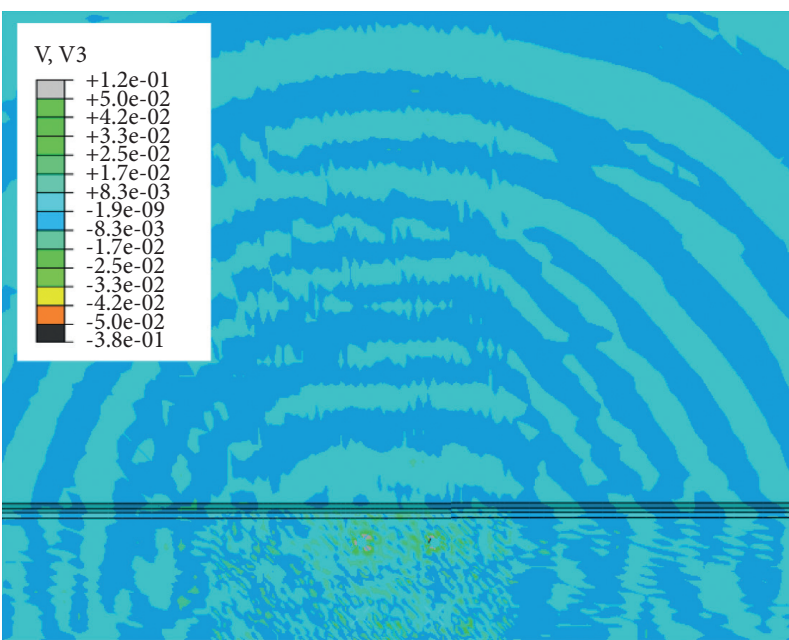

(a)

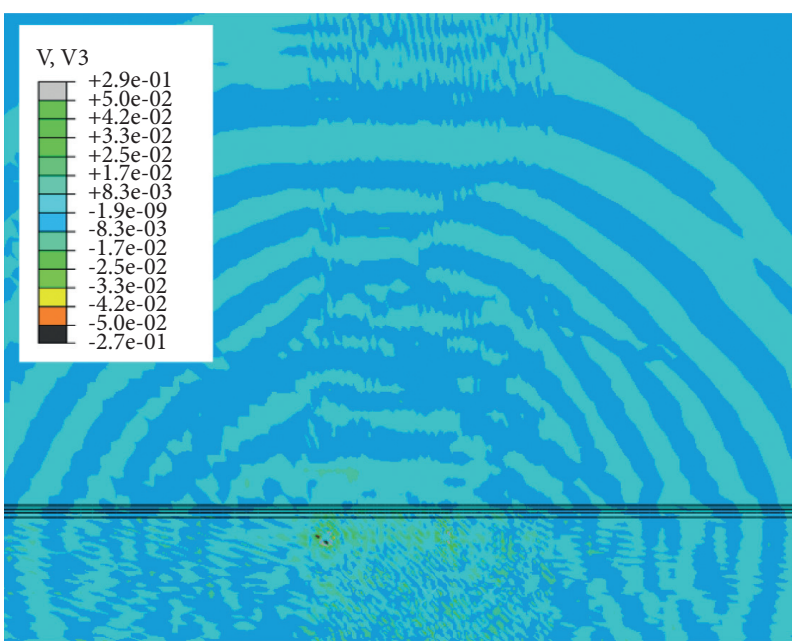

(c)

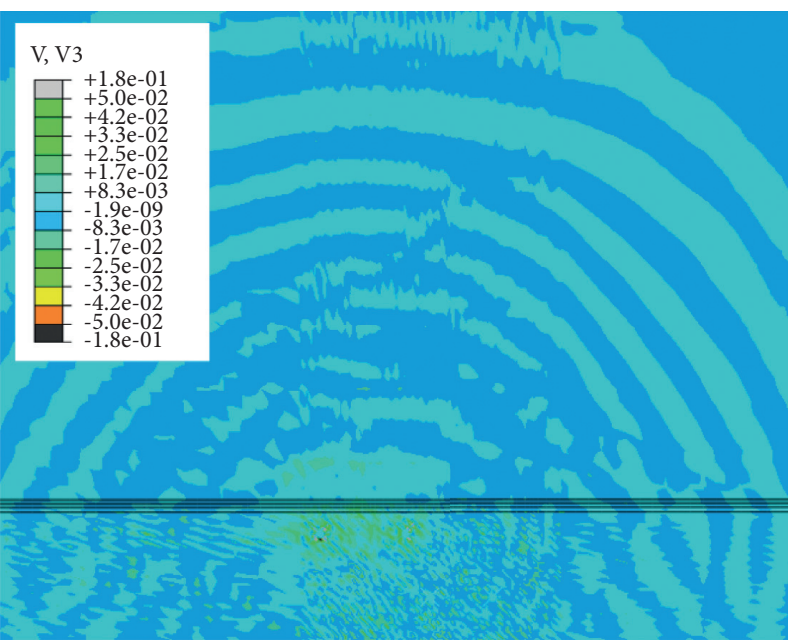

(b)

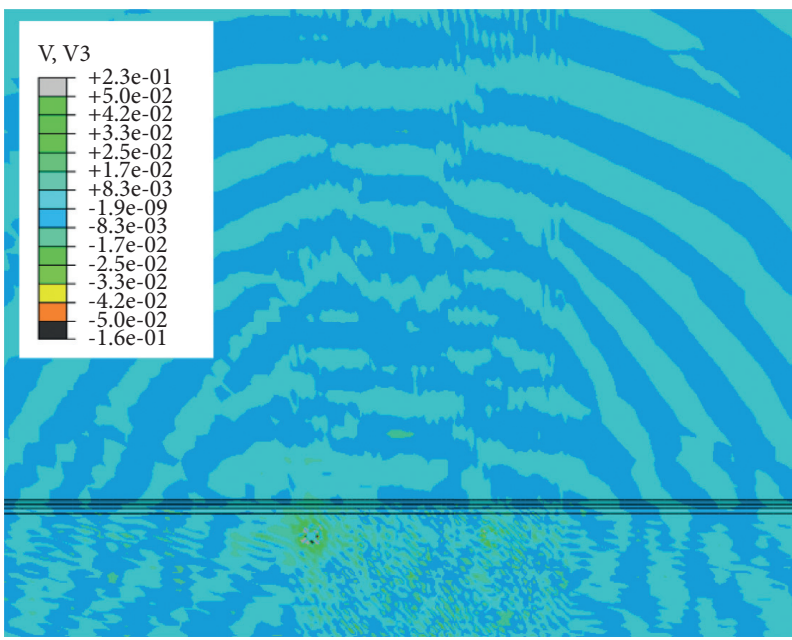

(d)

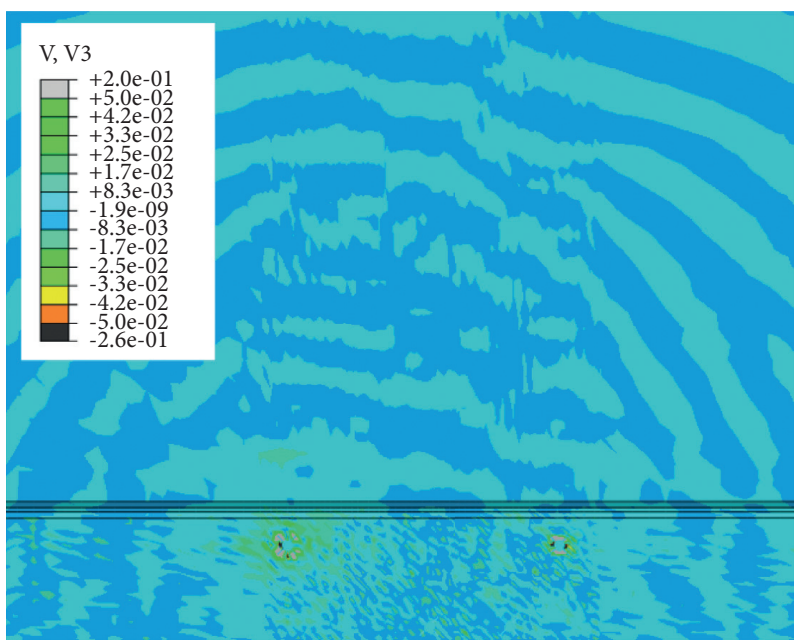

(e)

Figure 8: Comparison of the cloud plots of the peak vertical vibration velocities at different measuring points with different distances between the compactors ( $\mathrm{m} / \mathrm{s}$; for the horizontal arrangement): (a) two hammer distances of $15 \mathrm{~m}$, (b) two hammer distances of $20 \mathrm{~m}$, (c) two hammer distances of $30 \mathrm{~m}$, (d) two hammer distances of $40 \mathrm{~m}$, and (e) two hammer distances of $50 \mathrm{~m}$. 


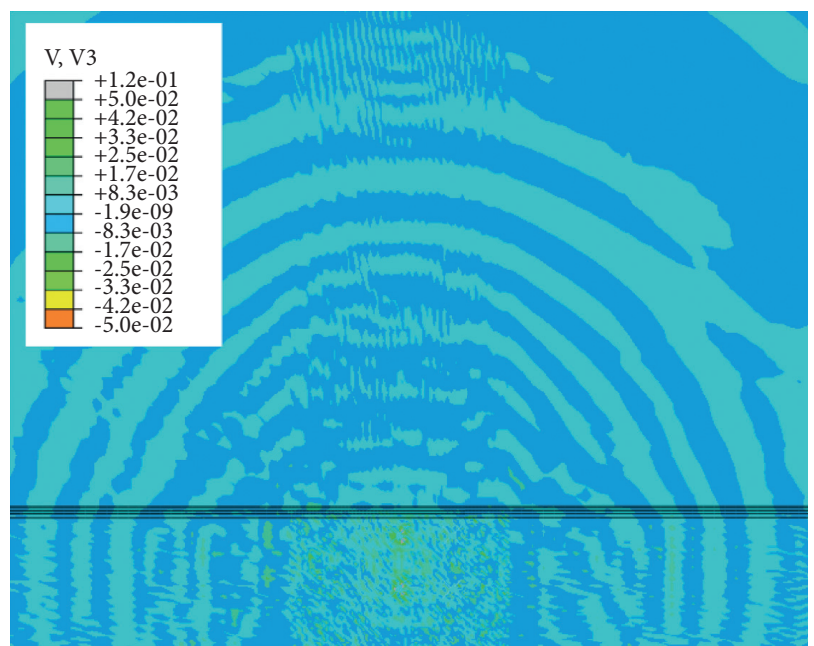

(a)

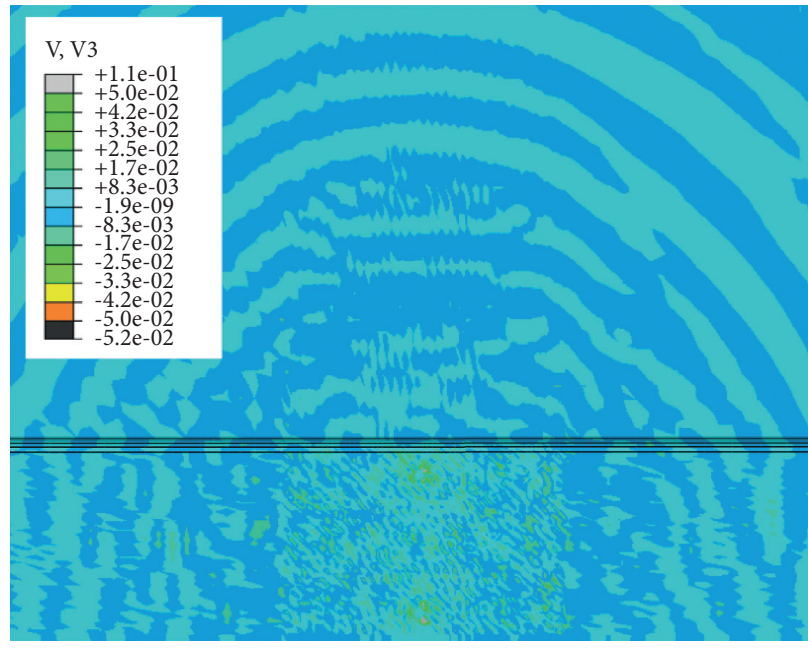

(c)

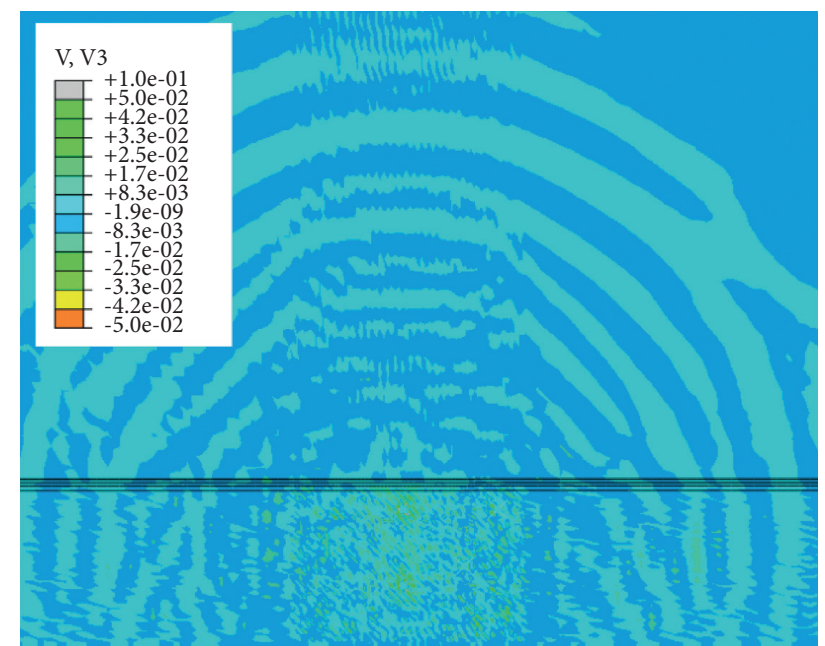

(b)

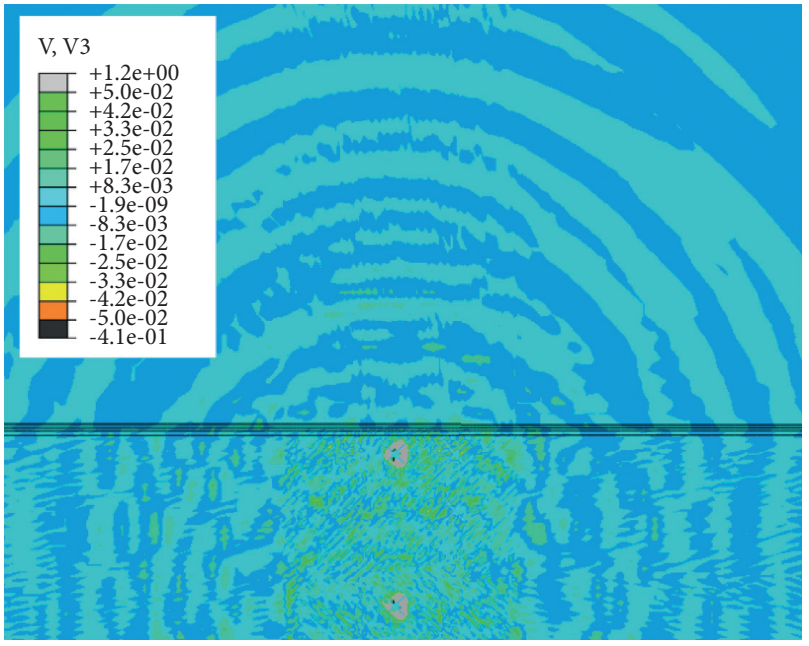

(d)

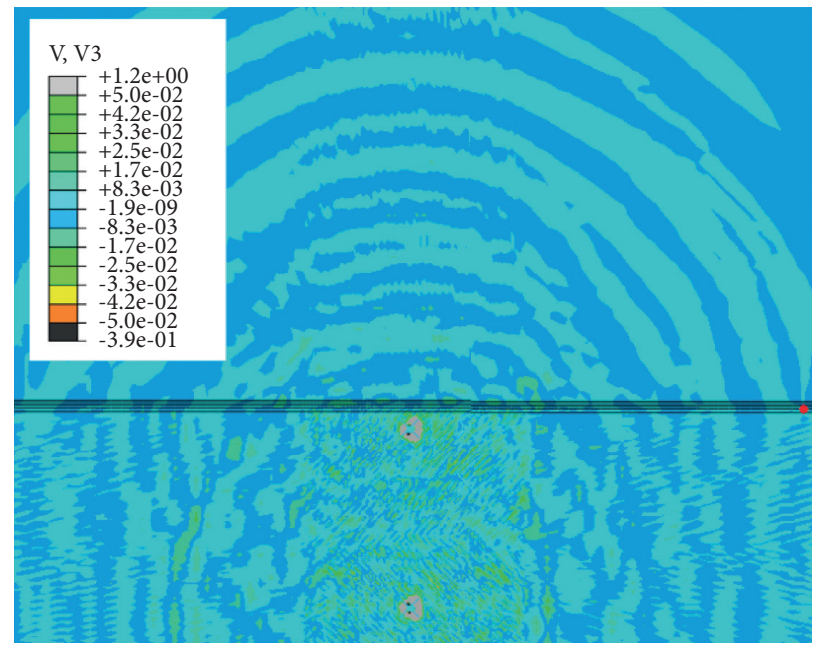

(e)

Figure 9: Comparison of the cloud plots of the peak vertical vibration velocities at different measurement points with different distances between the two hammers ( $\mathrm{m} / \mathrm{s}$; for the vertical arrangement): (a) two hammer distances of $15 \mathrm{~m}$, (b) two hammer distances of $20 \mathrm{~m}$, (c) two hammer distances of $30 \mathrm{~m}$, (d) two hammer distances of $40 \mathrm{~m}$, and (e) two hammer distances of $50 \mathrm{~m}$. 


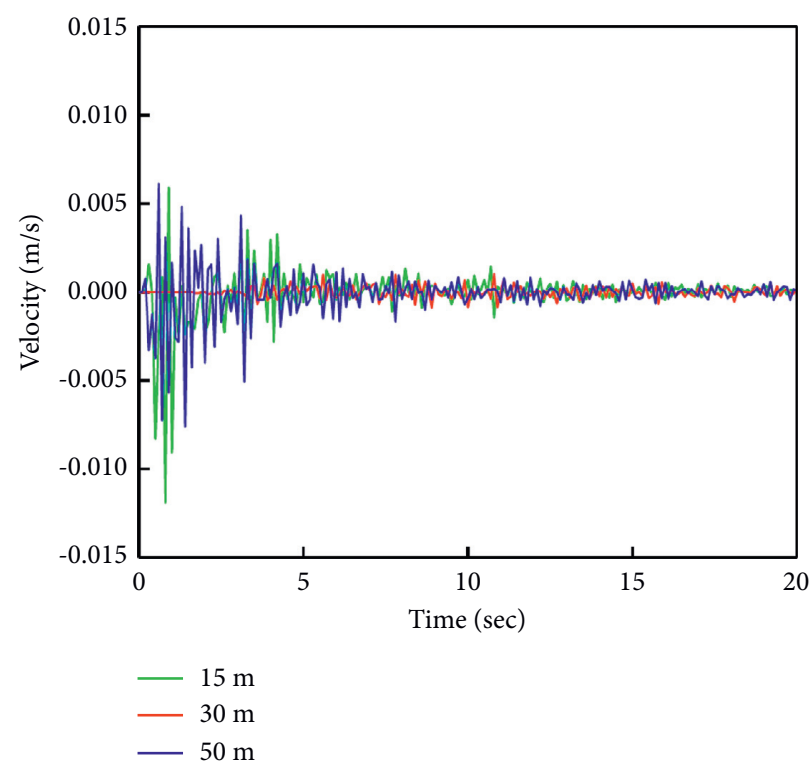

(a)

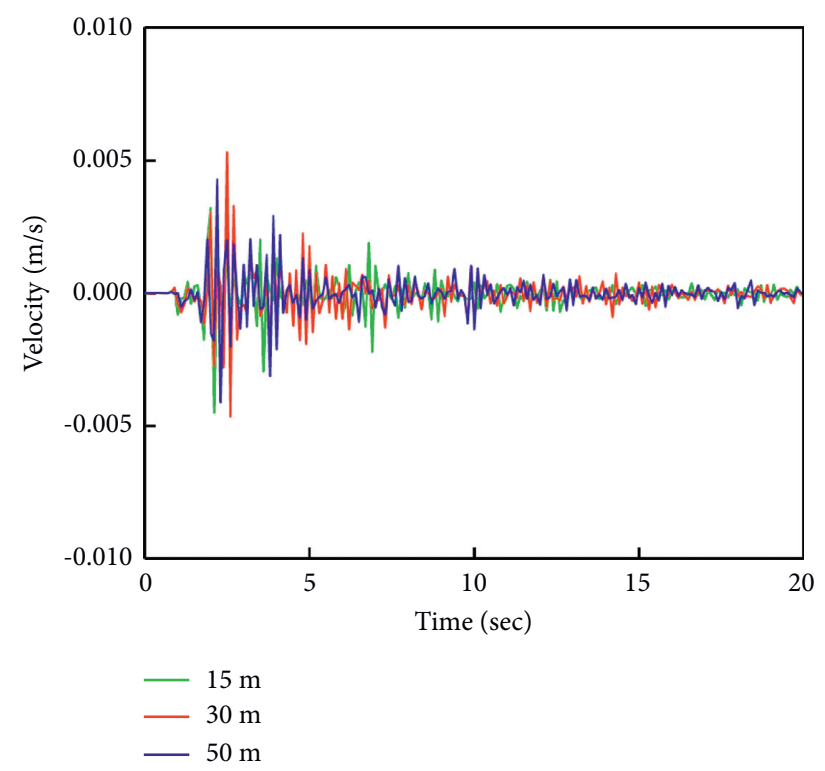

(b)

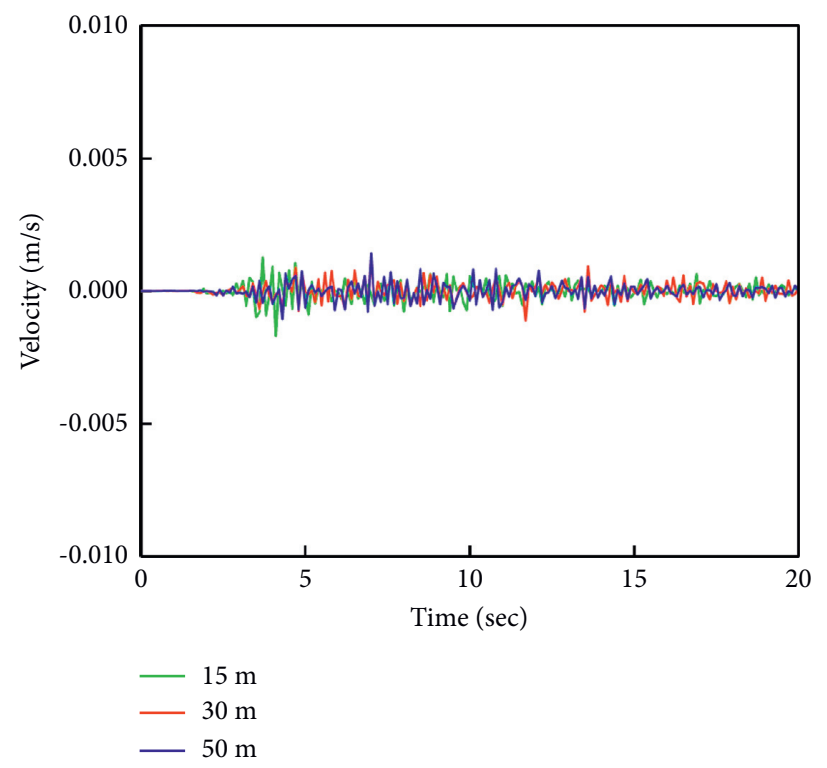

(c)

FIGURE 10: Comparison of the time-history curves for the peak vertical vibration velocities at different measuring points with different distances between the compactors (for the horizontal arrangement): (a) $50 \mathrm{~m}$ measuring point, (b) $100 \mathrm{~m}$ measuring point, and (c) $200 \mathrm{~m}$ measuring point.

Figure 14 is the cloud plot showing the distribution of the peak vertical vibration velocity of the ground $2 \mathrm{~s}$ after the hammer of the second compactor in a vertical arrangement landed on the ground. It can be seen from the figure that when the time interval between the two hammers was less than $5 \mathrm{~s}$, the tamping energy of the second hammer had a significant influence on the peak vertical vibration velocity of the ground. When the time interval between two hammers was greater than $5 \mathrm{~s}$, the trend of the ground vibration caused by the tamping energy of the second hammer was essentially similar to that of the single hammer compaction case. However, the energy superposition in the direction of the line connecting the hammer and the measuring point caused by the vertical arrangement had a lesser extent than that of the horizontal arrangement. The vibration velocity analysis is detailed in Figure 14.

It can be seen from Figure 15 that of the condition of two hammers with a time interval of less than $5 \mathrm{~s}$, the energy superposition was remarkable, the peak vertical vibration velocity became larger, and multiple peaks appeared. The energy attenuation with time also showed a significantly slower trend. As the time interval increased, the energy superposition began to be weakened. 


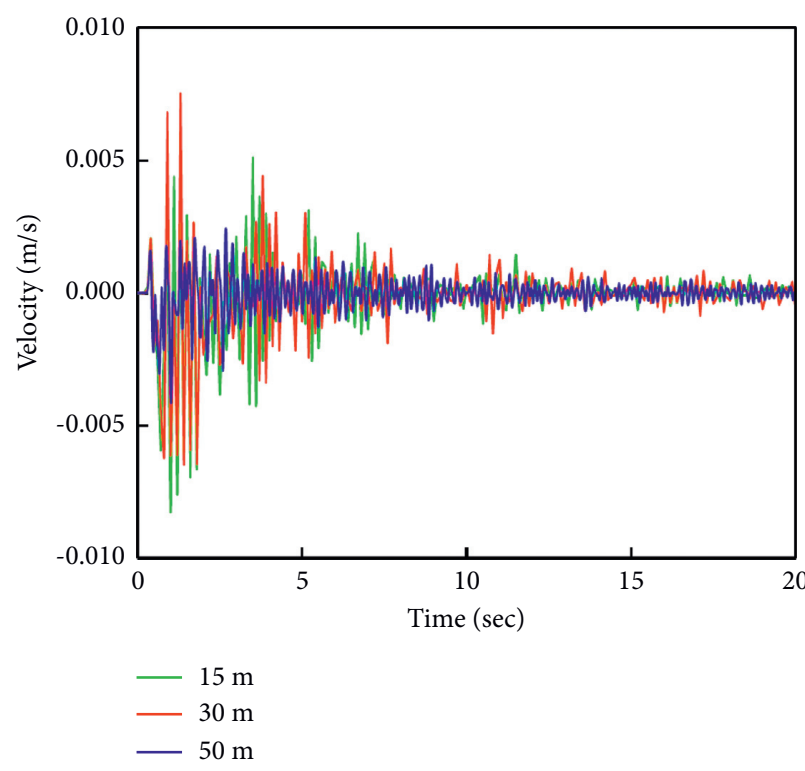

(a)

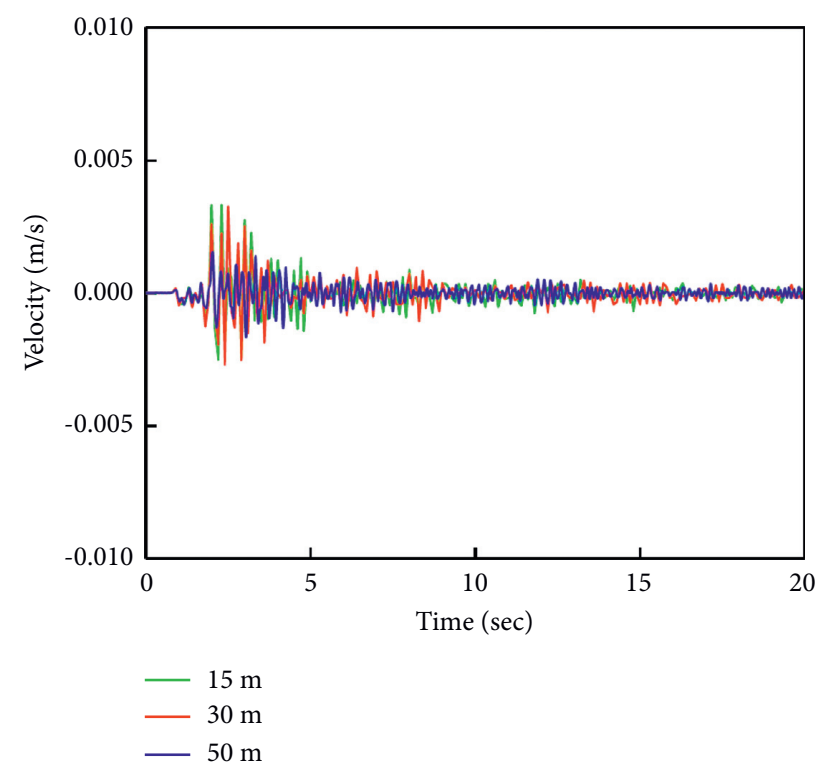

(b)

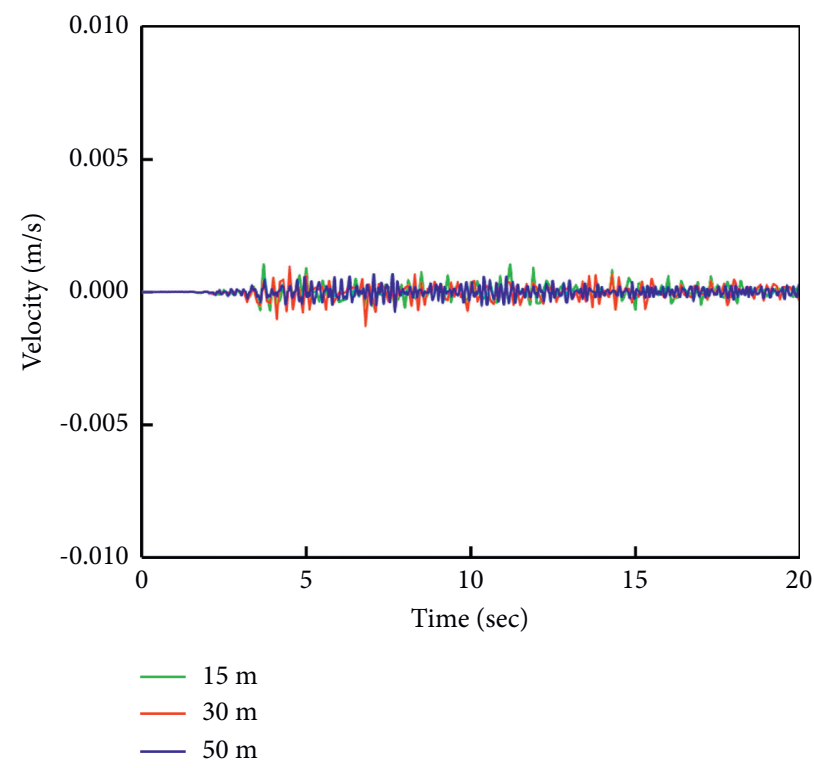

(c)

FIGURE 11: Comparison of the time-history curves of the peak vertical vibration velocities at different measuring points for the two-hammer condition with different time intervals (for the vertical arrangement): (a) $50 \mathrm{~m}$ measuring point, (b) $100 \mathrm{~m}$ measuring point, and (c) $200 \mathrm{~m}$ measuring point.

For soil in the near-field range, hammering with a time interval of less than $10 \mathrm{~s}$ led to a certain amount of energy superposition, the occurrence of multiple peaks, and a significantly slower trend of energy attenuation. For the mid-field range, the superposition of energy caused by hammering with a time interval of $5 \mathrm{~s}$ was less significant, and the energy attenuation trend was slower. For the farfield range, the superposition of energy caused by hammering at a time interval of more than $5 \mathrm{~s}$ could be generally ignored, and the compactions at a time interval of $10 \mathrm{~s}$ could be viewed as two different single-hammer compactions. According to the above analysis, the vertical arrangement caused less energy superposition but a longer duration than the horizontal arrangement.

3.4. Interaction between the Three Compactors Working Jointly. The case of three compactors was more complicated than the case of two compactors. Figures 15 and 16 show the cloud plots of the vertical vibration velocity of the site ground $1 \mathrm{~s}, 2 \mathrm{~s}$, and $4 \mathrm{~s}$ after the hammers landed on the ground for the different arrangements (linear and quincuncial) of the three compactors working simultaneously. 


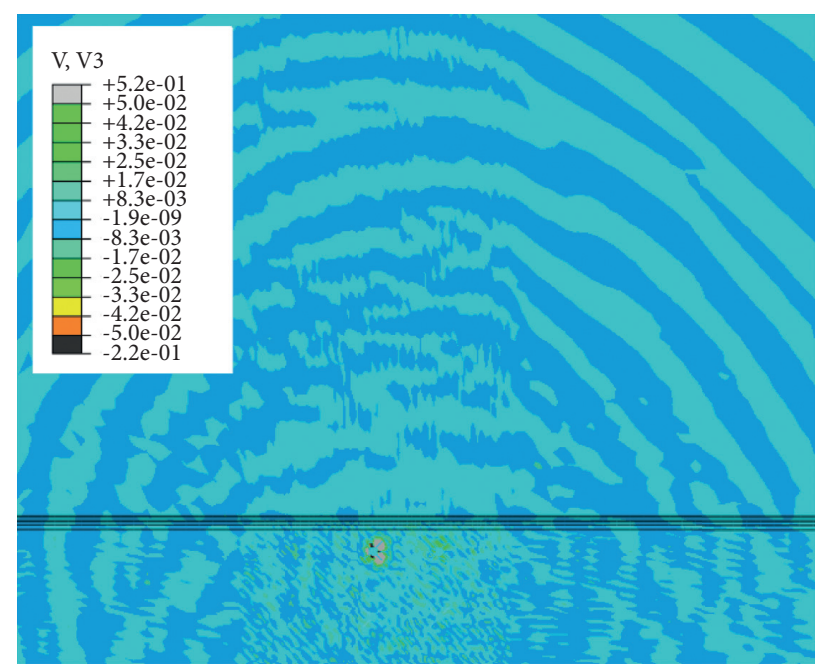

(a)

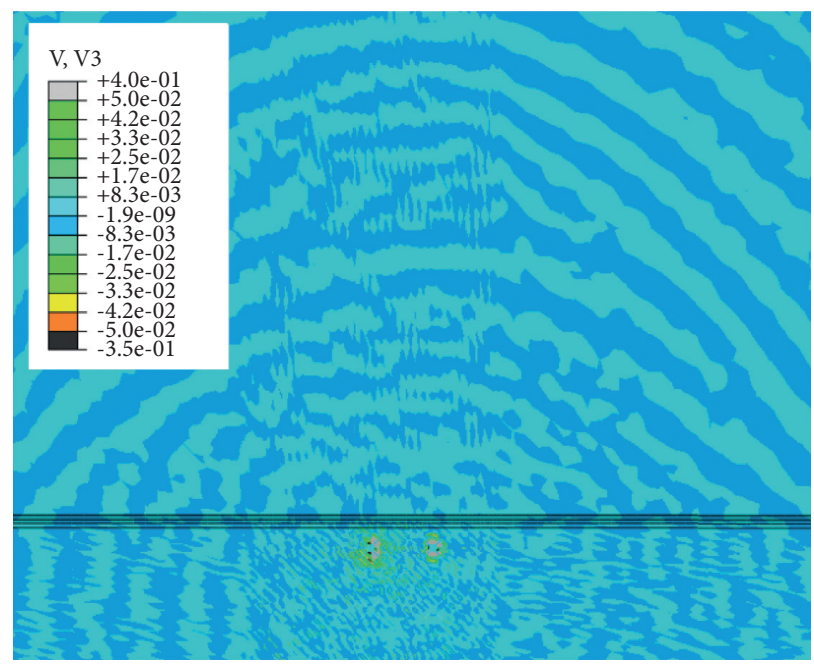

(c)

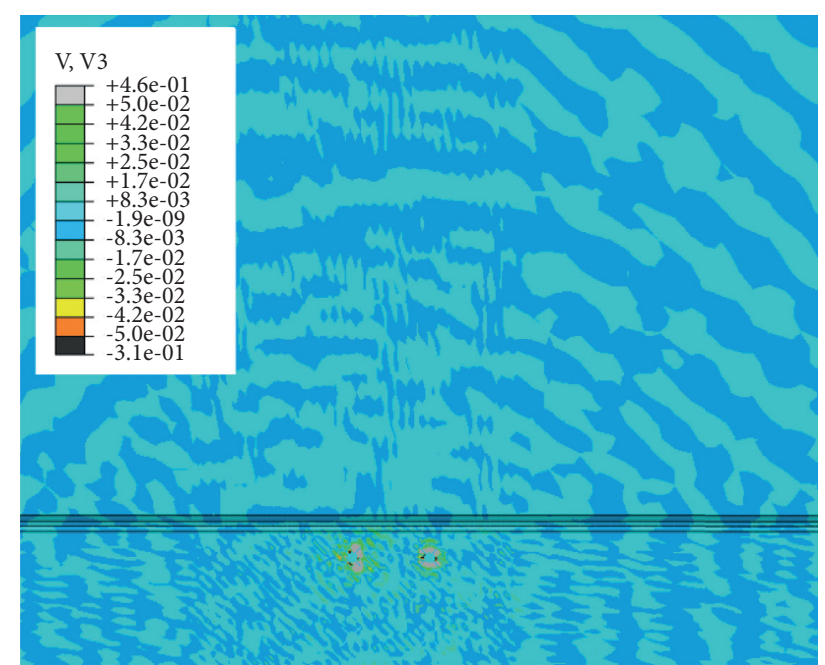

(b)

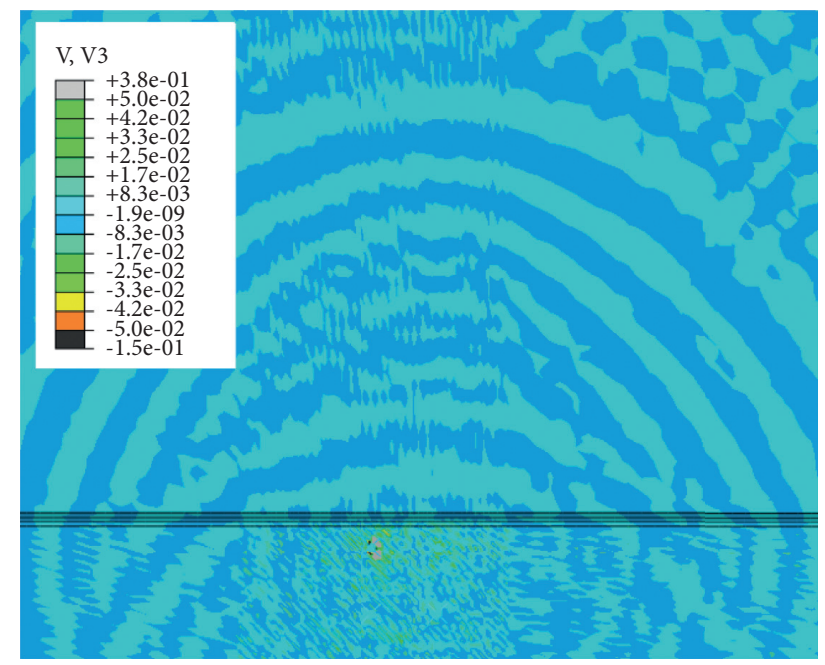

(d)

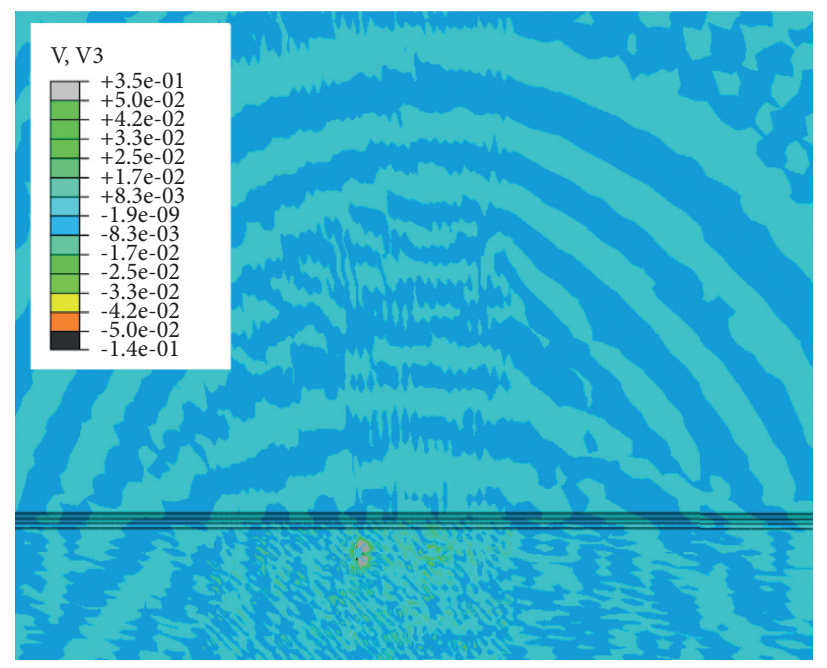

(e)

FIGURE 12: Comparison of the cloud plots of the peak vertical vibration velocities at different measuring points with different time intervals (m/s; for the horizontal arrangement): (a) $1 \mathrm{~s}$, (b) $3 \mathrm{~s}$, (c) $5 \mathrm{~s}$, (d) $8 \mathrm{~s}$, and (e) $10 \mathrm{~s}$. 

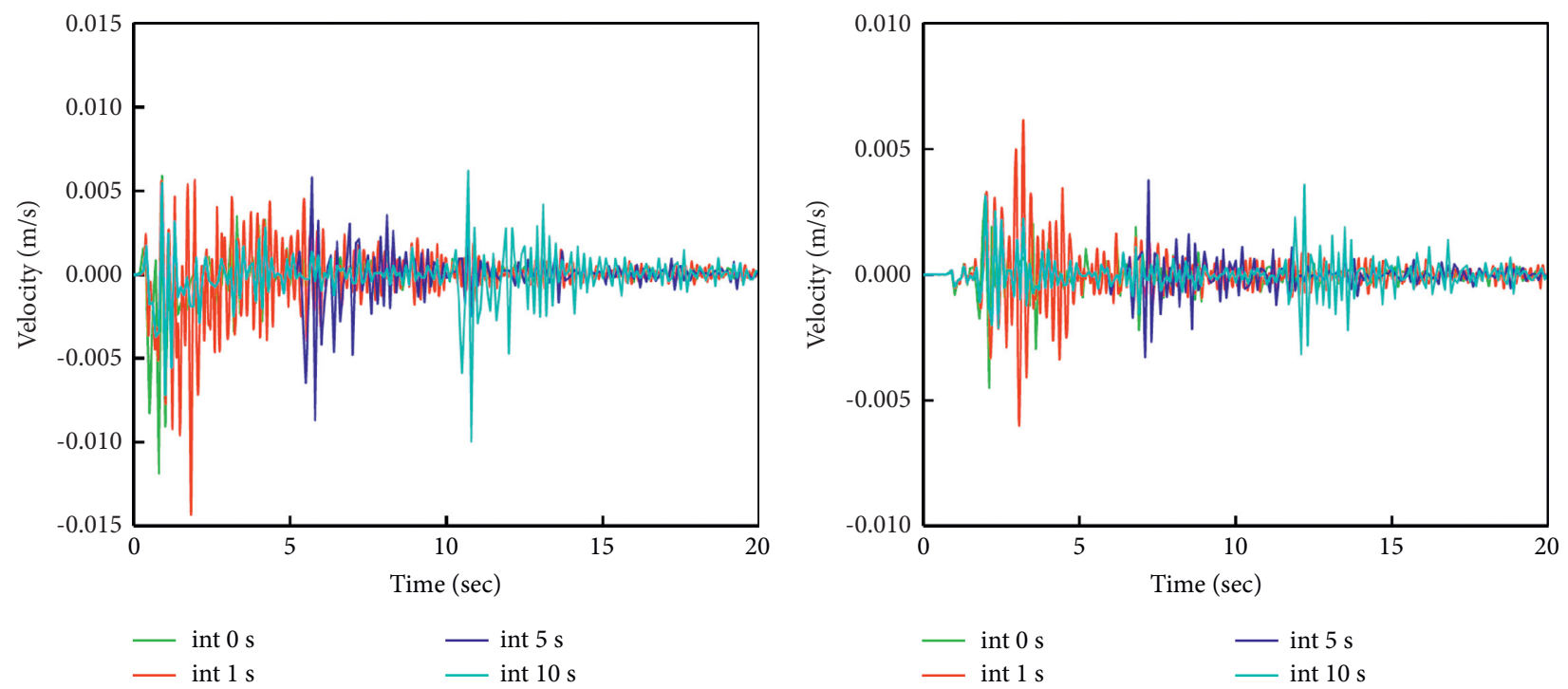

(a)

(b)

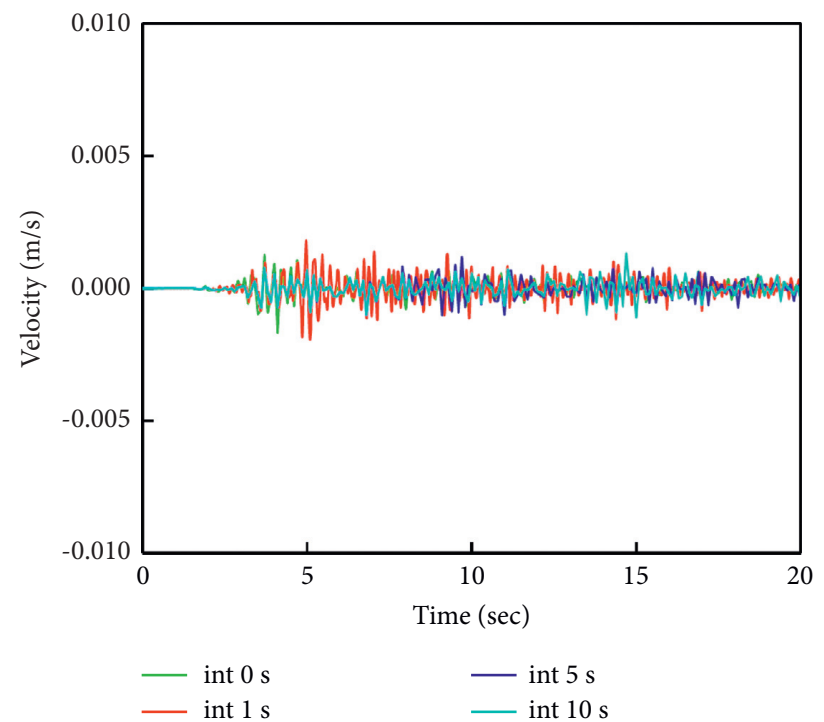

(c)

FIGURE 13: Time-history curves of the peak vertical peak vibration velocities at different measuring points with different time intervals (for the horizontal arrangement): (a) $50 \mathrm{~m}$ measuring point, (b) $100 \mathrm{~m}$ measuring point, and (c) $200 \mathrm{~m}$ measuring point.

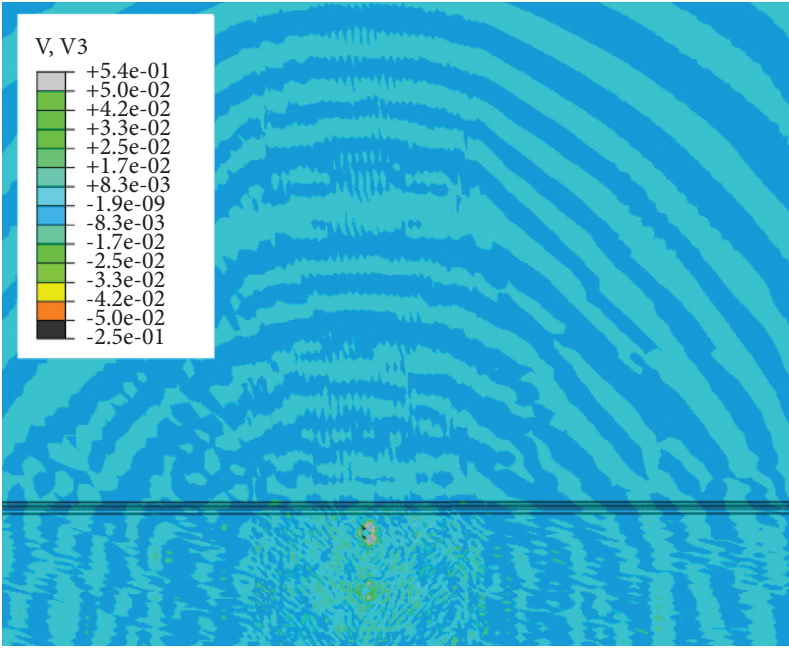

(a)

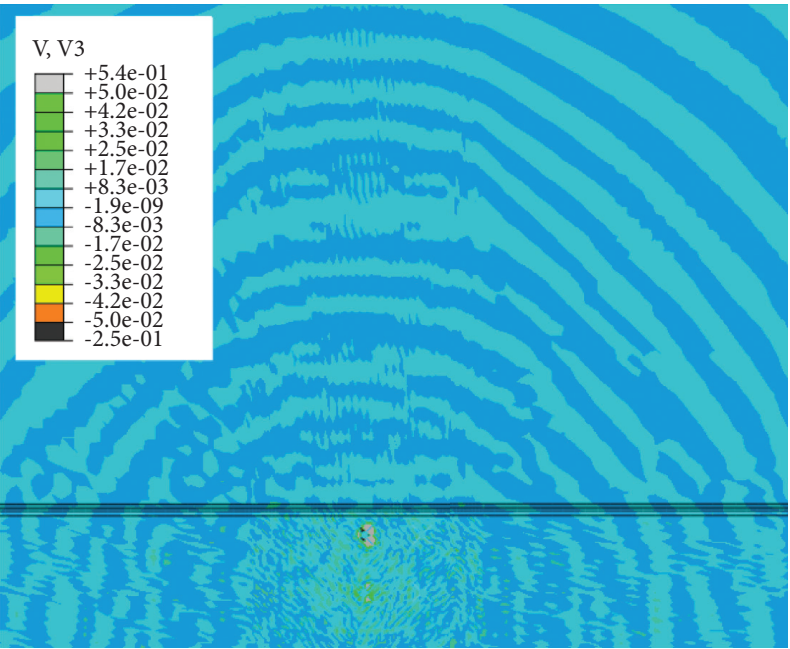

(b)

FIgURE 14: Continued. 


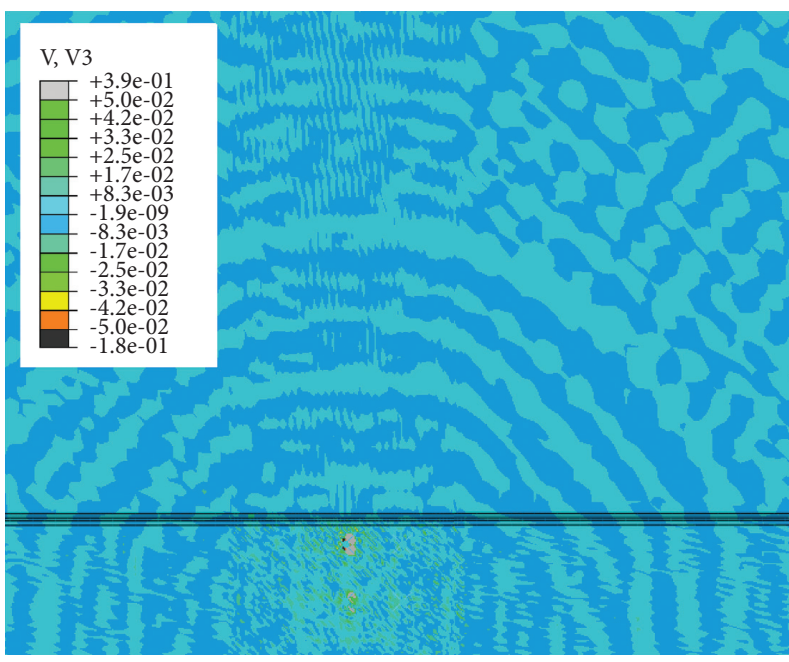

(c)

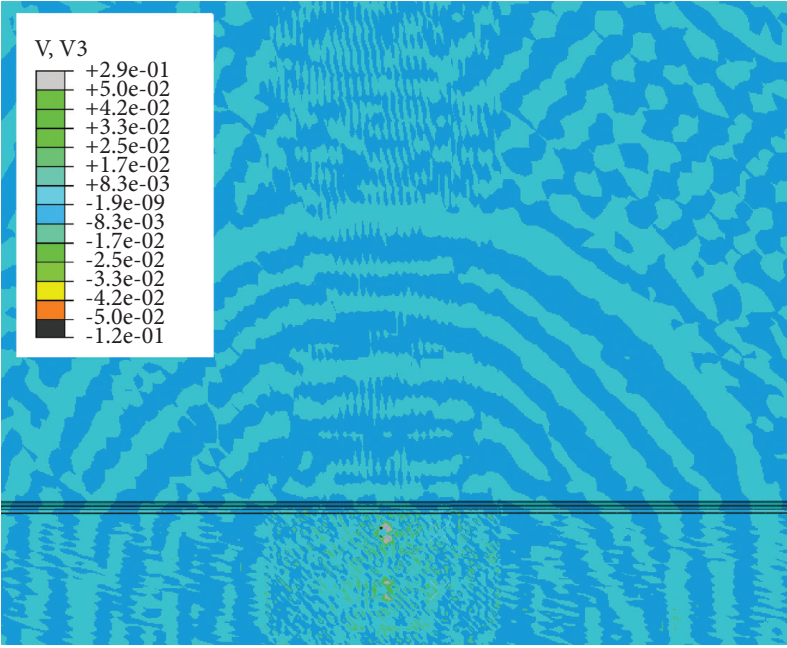

(d)

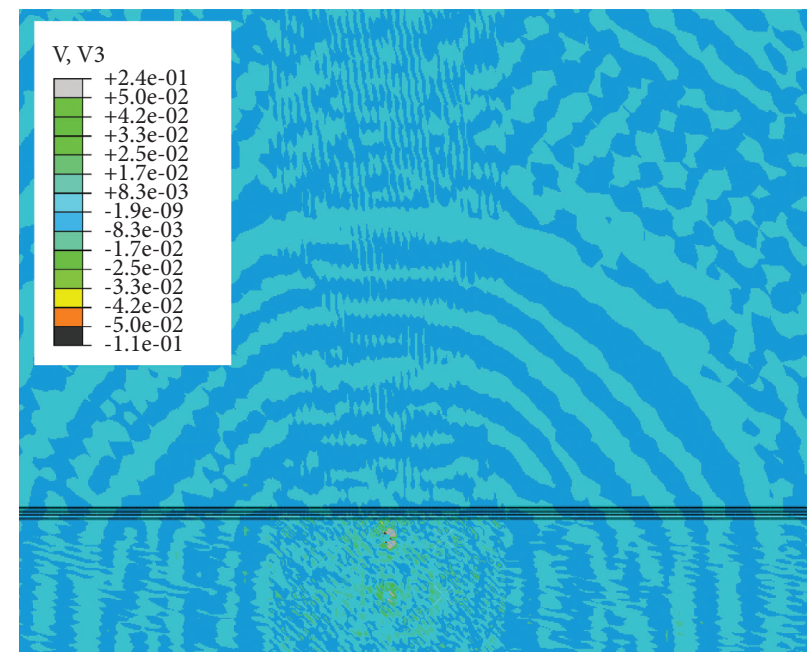

(e)

FIGURE 14: Cloud plots of the peak vertical vibration velocities at different measuring points with different time intervals ( $\mathrm{m} / \mathrm{s}$; for the vertical arrangement): (a) $1 \mathrm{~s}$, (b) $3 \mathrm{~s}$, (c) $5 \mathrm{~s}$, (d) $8 \mathrm{~s}$, and (e) $10 \mathrm{~s}$.

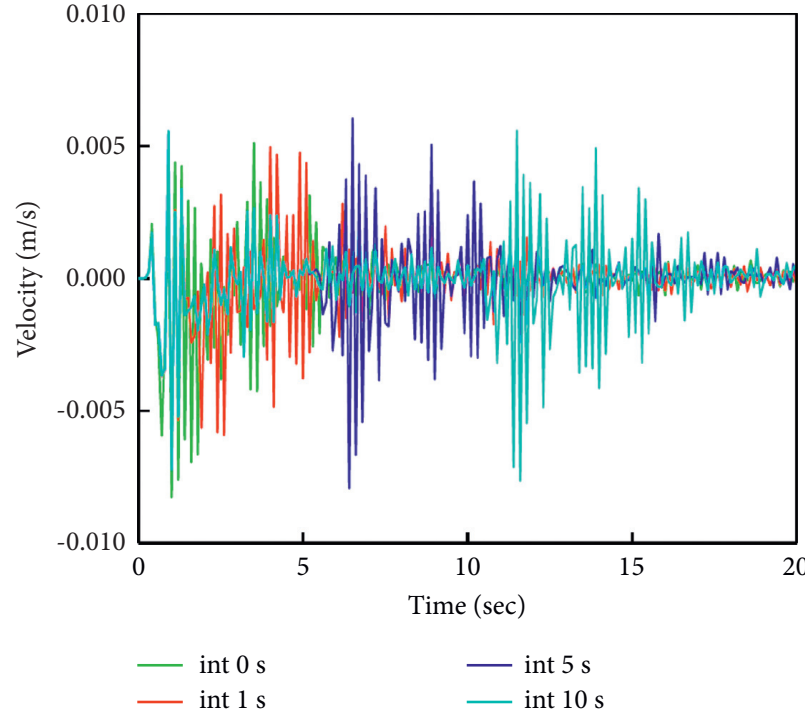

(a)

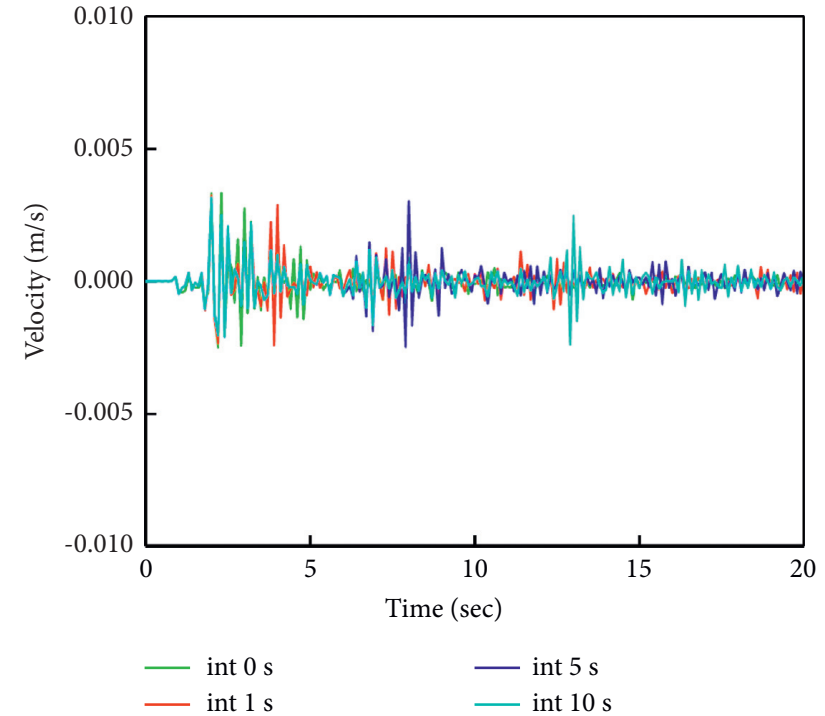

(b)

Figure 15: Continued. 


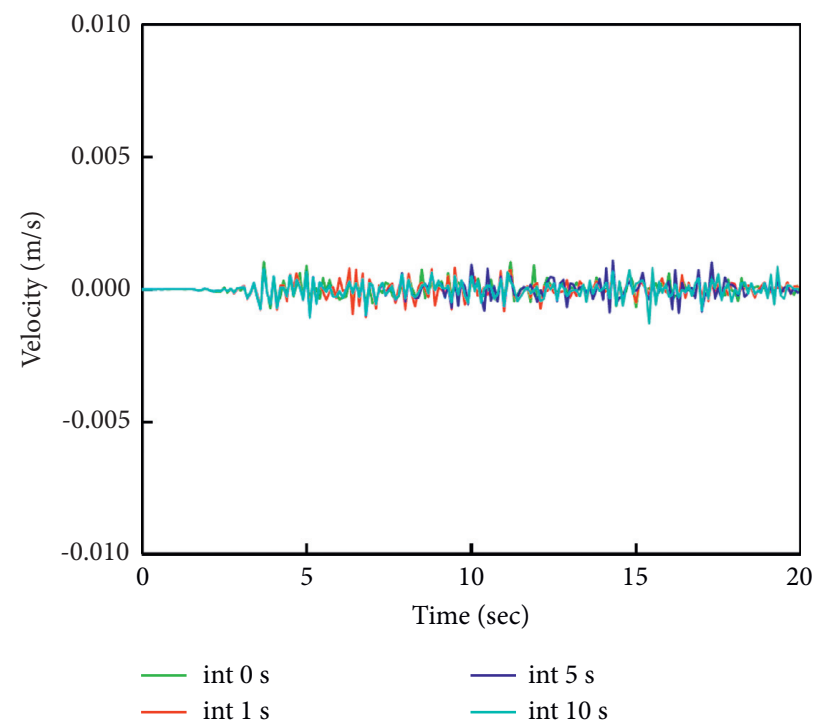

(c)

FIGURE 15: Time-history curves of the peak vertical vibration velocities at different measuring points with different time intervals (for the vertical arrangement): (a) $50 \mathrm{~m}$ measuring point, (b) $100 \mathrm{~m}$ measuring point, and (c) $200 \mathrm{~m}$ measuring point.

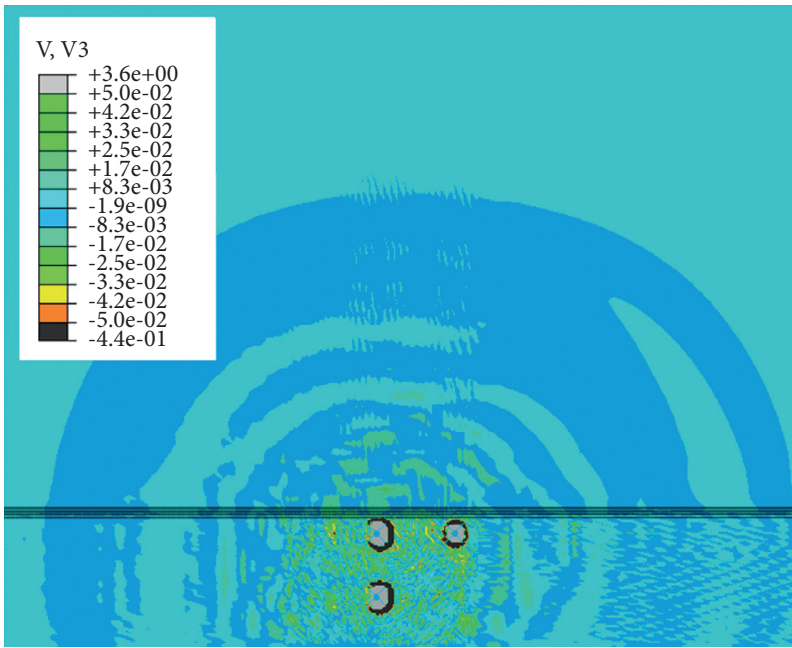

(a)

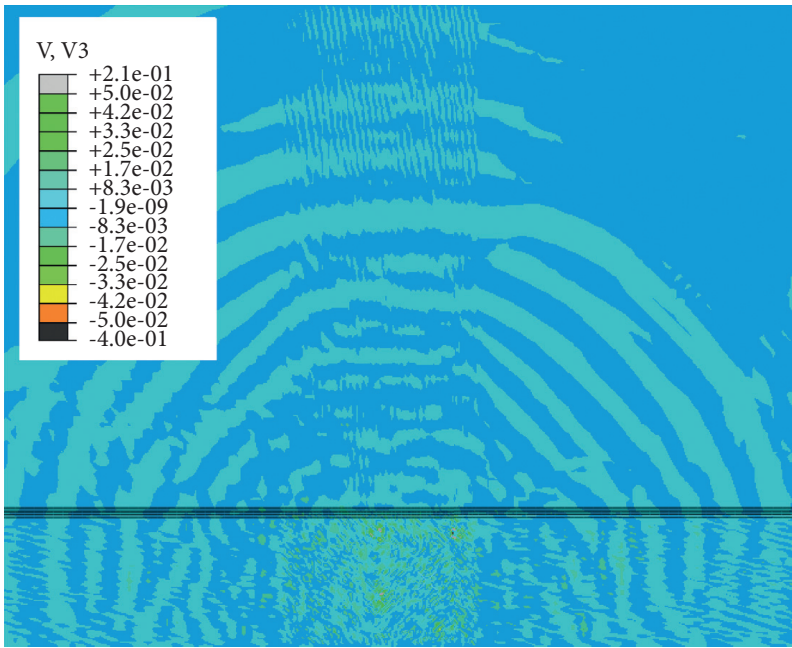

(b)

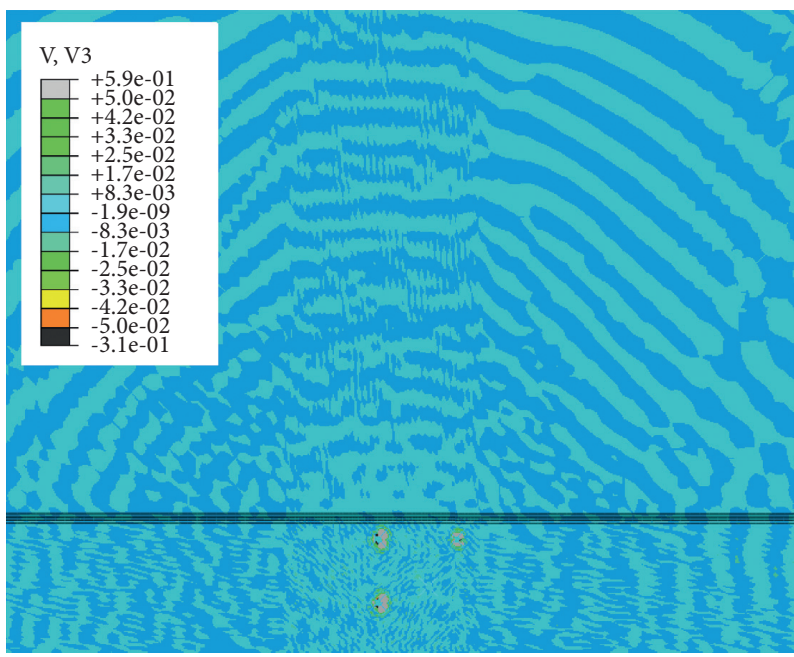

(c)

FIGURE 16: Comparison of the cloud plots of the peak velocity velocities at different times ( $\mathrm{m} / \mathrm{s}$; for the linear arrangement): (a) $1 \mathrm{~s}$, (b) $2 \mathrm{~s}$, and (c) $4 \mathrm{~s}$. 


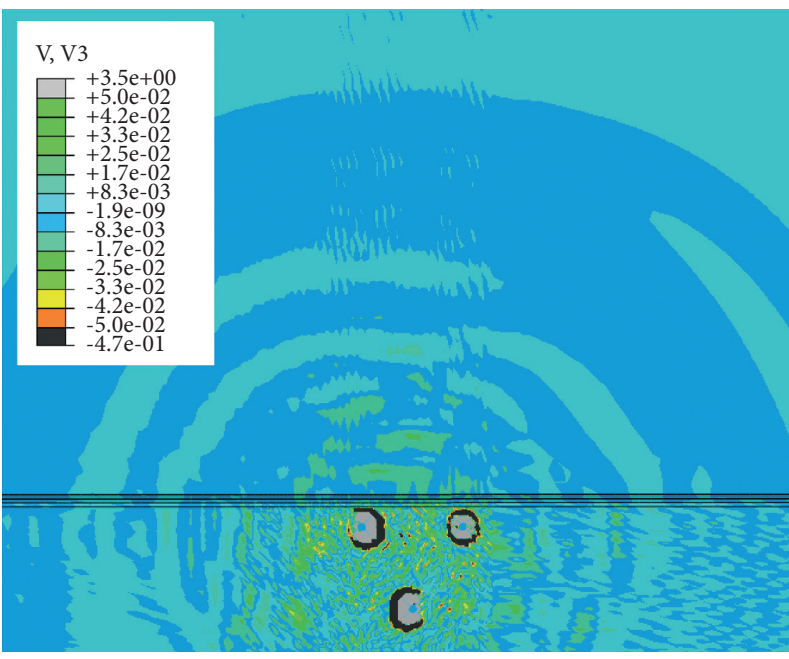

(a)

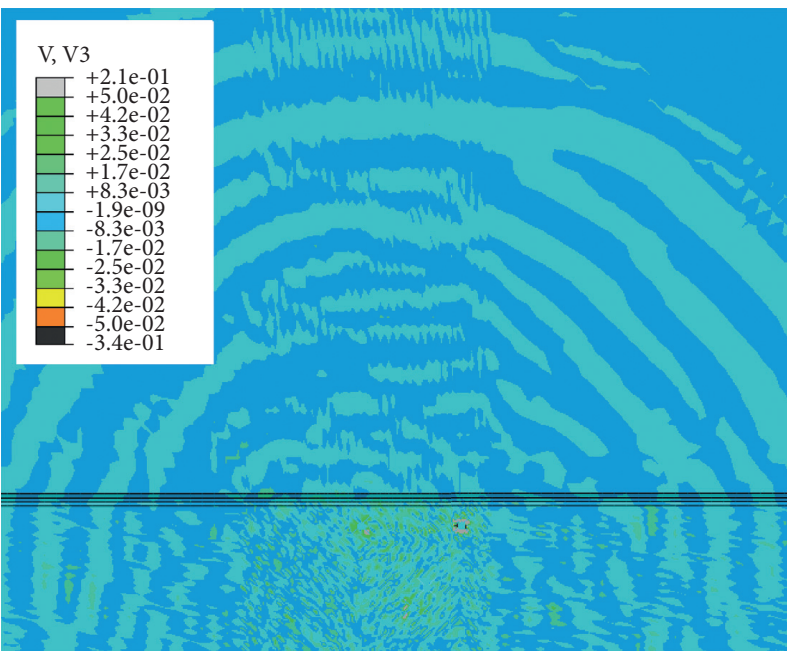

(b)

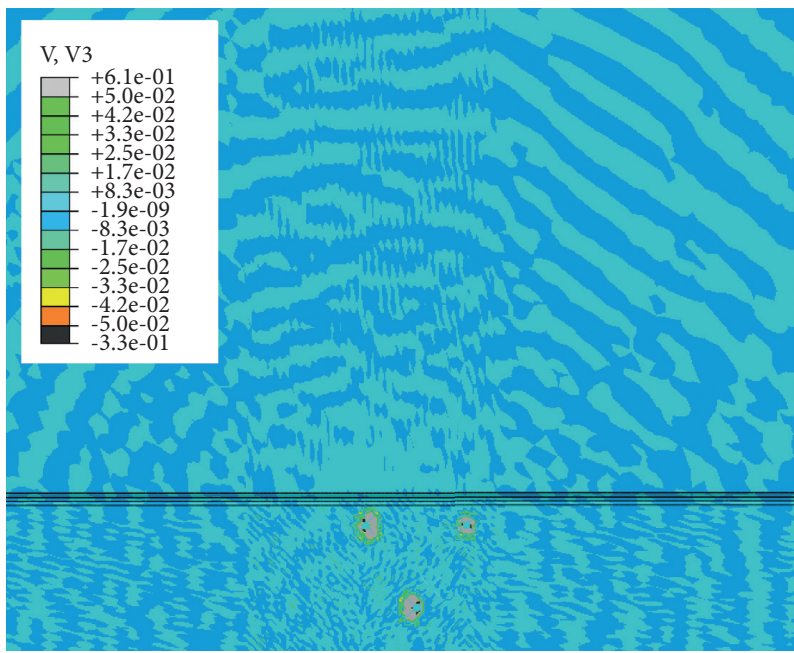

(c)

FIgURE 17: Comparison of the peak vibration velocities for the three-hammer condition at different times (m/s; for the quincuncial arrangement): (a) $1 \mathrm{~s}$, (b) $2 \mathrm{~s}$, and (c) $4 \mathrm{~s}$.

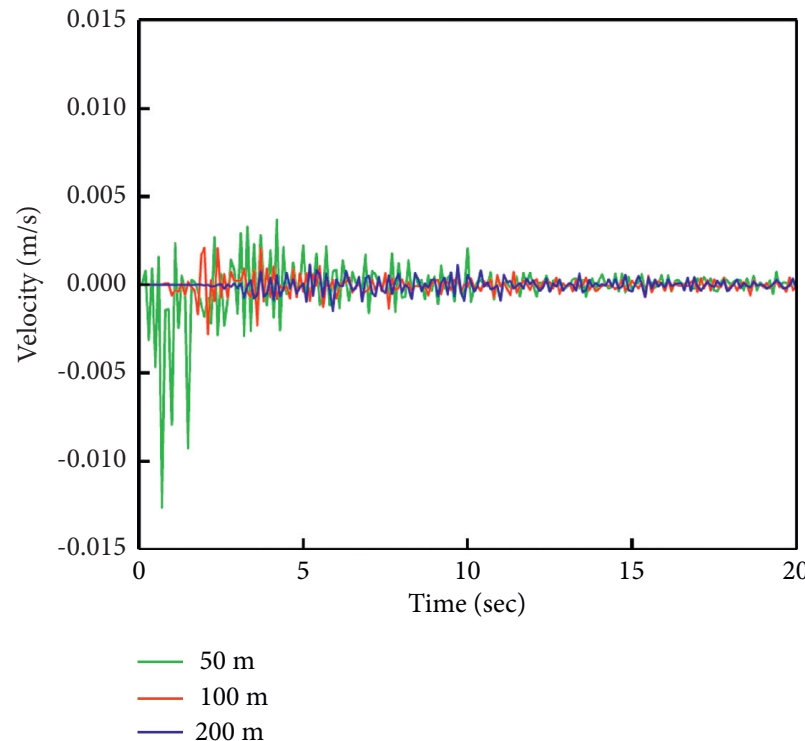

(a)

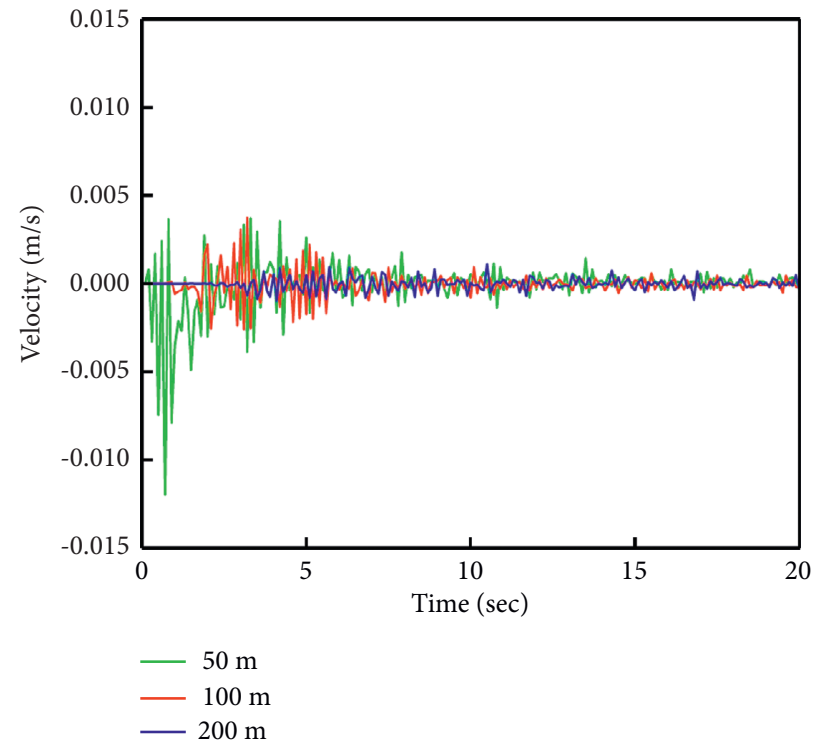

(b)

Figure 18: Comparison of the vertical vibration velocity histories for different combinations: (a) linear arrangement and (b) quincuncial arrangement. 
It can be seen from Figures 16 and 17 that the supposition of the vibration energy of the site was very complicated during the three-hammer compaction process. The influence of the quincuncial arrangement was greater than that of the linear arrangement. The specific comparison is shown in Figure 18.

It can be seen from the figure that for the near field, the three-hammer working condition had a significant and very complicated impact on the near field, with a high peak vibration velocity. For the mid field, there were a number of closely located peak vibration velocities with long durations. For the far field, the peak vibration velocity was higher than those of the two- and the single-hammer cases. Considering the stability and the construction safety of important surrounding structures, it is not recommended that three compactors work jointly in the same dynamic compaction subarea.

\section{Conclusions}

In this study, the impact of the high-energy DCM of multiple compactors on the rock-soil body of a site and the corresponding energy attenuation pattern were investigated using the explicit finite element module in ABAQUS. Factors such as the arrangement, spacing, and time interval of the compactors have been comparatively analyzed while taking into account the engineering practice. The following main conclusions were drawn:

(1) For the case of two compactors working simultaneously, different arrangements resulted in significantly different site ground vibrations. For the eastwest (horizontal) arrangement, the amplitude of the ground vibration in the area close to the tamping point was significantly enhanced. For the northsouth (vertical) arrangement, the amplitude of the ground vibration in the area closer to the tamping point did not change significantly, while the peak vertical ground vibration velocity clearly had multiple peaks, and the rate and the amplitude of the energy attenuation were both less than those of the horizontal arrangement.

(2) For the horizontal arrangement, as the distance between the two compactors increased, for the soil in the near-field range $(<50 \mathrm{~m})$, the peak vertical vibration velocity gradually decreased but still maintained a high value. For the soil in the mid field $(<100 \mathrm{~m})$, the peak value occurred with a delay, and the rate of energy attenuation gradually decreased. For the soil in the far-field range $(>200 \mathrm{~m})$, the distance between compactors had no significant influence.

For the vertical arrangement and for the soil in the near-field range, multiple peak vibration velocities appeared, and the energy attenuation rate was significantly slower. For the soil in the mid-field range, the peak vertical vibration velocities occurred with a delay, and the energy attenuation rate was higher than that of the near-field soil. For the soil in the far- field range, the peak vertical vibration velocity always maintained a small amplitude, but the peak occurred with a significant delay. Compared with that for the horizontal arrangement, for the vertical arrangement, the influence of the energy superposition decreased remarkably, but the peak occurred later as the distance increased.

(3) For the case of two compactors not tamping simultaneously with the horizontal arrangement for the soil in the near-field range, hammering with a time interval of less than $10 \mathrm{~s}$ led to significant energy superposition, the occurrence of multiple peaks, and a slower rate of the energy attenuation trend. For the mid-field range, the superposition of energy caused by hammering with a time interval greater than $5 \mathrm{~s}$ became insignificant, and the energy attenuation trend was close to that of the single hammer case. For the far-field range, the superposition of energy caused by hammering at a time interval of more than $5 \mathrm{~s}$ could be generally ignored, and the compactions at a time interval of $10 \mathrm{~s}$ could be regarded as two different single-hammer compactions.

For the vertical arrangement and for the near-field soil, hammering with a time interval of less than $10 \mathrm{~s}$ led to a certain amount of energy superposition, the occurrence of multiple peaks, and a significantly slower rate for the energy attenuation trend. For the mid field, the superposition of energy by hammering with a time interval of more than $5 \mathrm{~s}$ became insignificant, but the energy attenuation trend became slower. For the far-field range, the superposition of energy caused by hammering with a time interval of more than $5 \mathrm{~s}$ could be essentially ignored. The compactions with a time interval of $10 \mathrm{~s}$ could be regarded as two different single-hammer compactions. Compared with the horizontal arrangement, the vertical arrangement led to a lesser extent of energy superposition, but the superposition had an increased duration.

(4) The case of three compactors working simultaneously had a significant and very complicated impact on the near field, with a high peak vibration velocity. For the mid field, there were multiple closely located peak vibration velocities with long durations. For the far field, the peak vibration velocity was higher than those of the two- case and single-compactor case. When the impact of a DCM vibration needs to be considered, it is not recommended that three compactors work jointly in the same dynamic compaction subarea.

To summarize, when two-hammer compaction needs to be used in the same dynamic compaction area for dynamic compaction construction, a vertical arrangement in which two compactors are placed along a line that is parallel to the line connecting the key structure and the tamping point should be best used. Additionally, the distance between the two should be kept to $30 \mathrm{~m}$ or 
more, and the time interval should be at least $5 \mathrm{~s}$. If the key structure is located in the near-field range, a vertical arrangement should be best chosen. If the key structure is located in the mid-field range, a horizontal arrangement should be selected. If the key structure is located in the far-field range, the arrangement of compactors has no remarkable impact.

\section{Data Availability}

The data used to support the findings of this study are available from the corresponding author upon request.

\section{Conflicts of Interest}

The authors declare that there are no conflicts of interest.

\section{Acknowledgments}

This work was supported by the National Natural Science Foundation of China (no. 41302225) and the Shandong Jiaotong University'Climbing'Research Innovation Team Program.

\section{References}

[1] Q. Meng, J. Qiao, and L. Wang, "Model test study on transfer law of dynamic stress produced by dynamic compaction," Systems Engineering Procedia, vol. 1, pp. 74-79, 2011.

[2] S.-J. Feng, K. Tan, W.-H. Shui, and Y. Zhang, "Densification of desert sands by high energy dynamic compaction," Engineering Geology, vol. 157, pp. 48-54, 2013.

[3] A. Ghassemi, A. Pak, and H. Shahir, "Numerical study of the coupled hydro-mechanical effects in dynamic compaction of saturated granular soils," Computers and Geotechnics, vol. 37, no. 1-2, pp. 10-24, 2010.

[4] L. Ménard and Y. Broise, "Theoretical and practical aspects of dynamic consolidation," Ground treatment by deep compaction, Thomas Telford Publishing, vol. 25, pp. 3-18, 1976.

[5] C. Liao, J. Chen, and Y. Zhang, "Accumulation of pore water pressure in a homogeneous sandy seabed around a rocking mono-pile subjected to wave loads," Ocean Engineering, vol. 173, pp. 810-822, 2019.

[6] W. Wang, J.-J. Chen, and J.-H. Wang, "Estimation method for ground deformation of granular soils caused by dynamic compaction," Soil Dynamics and Earthquake Engineering, vol. 92, pp. 266-278, 2017a.

[7] R. Zhang, Y. Sun, and E. Song, "Simulation of dynamic compaction and analysis of its efficiency with the material point method," Computers and Geotechnics, vol. 116, 2019.

[8] X. Li, J. Li, X. Ma, T. Jidong, and Z. Sheng, "Numerical study of the dynamic compaction process considering the phenomenon of particle breakage," Advances in Civil Engineering, vol. 2018, Article ID 1838370, 10 pages, 2018.

[9] A. E. Mayer, A. A. Ebel, and M. K. A. Al-Sandoqachi, "Plastic deformation at dynamic compaction of aluminum nanopowder: molecular dynamics simulations and mechanical model," International Journal of Plasticity, vol. 124, pp. 22-41, 2020.

[10] J. Wang, Y. Cui, and Q. Li, "Hybrid numerical investigation on soil-hammer interaction during dynamic compaction," Advances in Civil Engineering, vol. 2019, no. 12, 11 pages, Article ID 4563134, 2019.
[11] H. Kardgar, "Investigation of the bearing capacity of foundations on encased stone columns using finite element method," Int. J. Integr. Eng.vol. 10, pp. 103-108, 2018.

[12] L. Fang, F. Jing, and S. Y. Liu, "Influence of vibration caused by dynamic compaction and safe distances for building," Journal of South East University(Natural Science Edition), vol. 31, no. 5, pp. 29-32, 2001.

[13] R. Li, W. B. Jian, and R. T. Kang, "Vibration attenuation laws for reinforcing filled ground by dynamic compaction," Chinese Journal of Geotechnical Engineering, vol. 33, no. Supp.1, pp. 253-257, 2011.

[14] J. B. Peng, Study on Vibration Characteristics of Strata and Buildings Caused by Dynamic Compaction and its Control, Master's Thesis. Hunan University of Science and Technology, Hunan, 2012.

[15] S.-W. Son, P. Bagheri, and J.-M. Kim, "Dynamic behavior of ground improved using a crushed stone foundation wall," Sustainability, vol. 11, no. 10, p. 2767, 2019.

[16] K. Mostafa, Numerical Modeling of Dynamic Compaction in Cohesive Soil, p. 182, Ph.D. Thesis. University of Akron, Akron. OH. USA, 2011.

[17] J.-S. Moon, H. S. Jung, S. Lee, and S.-T. Kang, "Ground improvement using dynamic compaction in sabkha deposit," Applied Sciences, vol. 9, no. 12, p. 2506, 2019.

[18] G. Zhang, Y. Yang, and F. Su, "Parameter optimization of geogrid-reinforced foundations based on model experiments and numerical simulations," Applied Sciences, vol. 9, no. 17, p. 3592, 2019.

[19] L. Zhang, G. Yang, D. Zhang, W. Zhijie, and J. Jing, "Field test and numerical simulation of dynamic compaction of high embankment filled with soil-rock," Advances in Civil Engineering, vol. 2019, no. 1, 9 pages, Article ID 6040793, 2019.

[20] J. L, "The study on the vibration characteristics of the ground surface in improving collapsible loess foundation with dynamic consolidation," Master's Thesis Cheng Du, Southwest Jiaotong University, 2009.

[21] Z. Li, "The study of relativity between heavy tamping vibration attenuation and ground medium character," Master's Thesis, China University of Geosciences, Bei Jing, 2003.

[22] C. M. Gong, Q. G. Cheng, and Z. P. Liu, "Model test study of dynamic responses of loess slope by dynamic compaction," Rock and Soil Mechanics, vol. 32, no. 7, pp. 2001-2006, 2011.

[23] M. Hajialilue-Bonab and F. S. Zare, "Investigation on tamping spacing in dynamic compaction using model tests," Proceedings of the Institution of Civil Engineers-Ground Improvement, vol. 167, no. 3, pp. 219-231, 2014.

[24] X. J. Lu, X. N. Gong, and J. G. Li, "Research on parameters of construction with dynamic method," Rock and Soil Mechanics, vol. 27, no. 9, pp. 1628-1632, 2006.

[25] J. G. Yang, W. X. Peng, and D. Y. Liu, "Research of choosing tamping factors for dynamic consolidation method," Rock and Soil Mechanics, vol. 25, no. 8, pp. 1135-1139, 2004.

[26] W. Wang, J. Dou, J. Chen, and J. Wang, "Numerical analysis of the soil compaction degree under multi-location tamping," Journal of Shanghai Jiaotong University, vol. 22, no. 4, pp. 417-433, 2017.

[27] D. A. Anderson, S. R. Winzer, and A. P. Ritter, "Synthetic delay versus frequency plots for predicting ground vibration from blasting," in Proceedings of the Third International Conference on Computer-Aided Seismic Analysis and Discrimination, pp. 70-74, Catholic University, Washington, DC, June 1983. 